\title{
Effects of Different Wall Shapes on Thermal-Hydraulic Characteristics of Different Channels Filled with Water Based Graphite-SiO $\mathrm{S}_{2}$ Hybrid Nanofluid
}

\author{
Yacine Khetib ${ }^{1,2, *}$, Ahmad Alahmadi ${ }^{3}$, Ali Alzaed ${ }^{4}$, Ahamd Tahmasebi ${ }^{5}$ (D), Mohsen Sharifpur ${ }^{6,7, *(\mathbb{D})}$ \\ and Goshtasp Cheraghian $8, *$ (D)
}

check for

updates

Citation: Khetib, Y.; Alahmadi, A.; Alzaed, A.; Tahmasebi, A.;

Sharifpur, M.; Cheraghian, G. Effects of Different Wall Shapes on

Thermal-Hydraulic Characteristics of Different Channels Filled with Water Based Graphite-SiO ${ }_{2}$ Hybrid

Nanofluid. Processes 2021, 9, 1253.

https://doi.org/10.3390/pr9071253

Academic Editor: Hussein

A. Mohammed

Received: 12 June 2021

Accepted: 16 July 2021

Published: 20 July 2021

Publisher's Note: MDPI stays neutral with regard to jurisdictional claims in published maps and institutional affiliations.

Copyright: (c) 2021 by the authors. Licensee MDPI, Basel, Switzerland. This article is an open access article distributed under the terms and conditions of the Creative Commons Attribution (CC BY) license (https:// creativecommons.org/licenses/by/ $4.0 /)$.
1 Mechanical Engineering Department, Faculty of Engineering, King Abdulaziz University, Jeddah 80204, Saudi Arabia

2 Center Excellence of Renewable Energy and Power, King Abdulaziz University, Jeddah 80204, Saudi Arabia

3 Department of Electrical Engineering, College of Engineering, Taif University, Taif 21944, Saudi Arabia; aziz@tu.edu.sa

4 Architectural Engineering Department, Faculty of Engineering, Taif University, Taif 21944, Saudi Arabia; alzaed@tu.edu.sa

5 Independent Researcher, Dubai 999041, United Arab Emirates; tahmaseby.ahmad@gmail.com

6 Department of Mechanical and Aeronautical Engineering, University of Pretoria, Hatfield 0028, South Africa

7 Department of Medical Research, China Medical University Hospital, China Medical University, Taichung 404, Taiwan

8 Technische Universität Braunschweig, 38106 Braunschweig, Germany

* Correspondence: ykhetib@yahoo.com (Y.K.); mohsen.sharifpur@up.ac.za (M.S.); g.cheraghian@tu-braunschweig.de (G.C.)

\begin{abstract}
In the current numerical study, various wall shape effects are investigated on the thermalhydraulic characteristics of different channels filled with water-based graphite- $\mathrm{SiO}_{2}$ hybrid nanofluid. In this work, the performance evaluation criteria (PEC) index is employed as the target parameter to attain optimum geometry. Six different cases are studied in this research, and each case has different geometrical dimensions. The inlet temperature for the fluids in the channel is $300 \mathrm{~K}$, over a range of different flow velocities. According to the obtained results, an increase in the volume fraction of nanoparticles results in higher PEC values. In addition, an increase in Reynolds number to $\operatorname{Re}=$ leads to an increase in the PEC index. The results clearly show that increasing the Reynolds number has two consequences: on the one hand, it increases the pressure drop penalty; on the other hand, it improves heat transfer. Therefore, the maximum value of the PEC index occurs at $\operatorname{Re}=15,000$.
\end{abstract}

Keywords: hybrid nanofluid; PEC; graphite-SiO 2 ; channel; different wall

\section{Introduction}

The use of different surfaces and nanofluids have always been recognized as two very effective solutions to improving heat exchanger performance [1-5]. However, the shape of the wall of the channel affects the hydraulic performance of the system, so geometries that have the smallest pressure drops are used. On the other hand, nanofluids have been widely used in recent years due to their unique properties [6-10]. Nanofluids can increase the heat transfer in heat devices [11-15]. Some researchers have used numerical methods to study nanofluids [16-20]. Nakharintr and Naphon [21] studied the thermal hydraulic characteristics of $\mathrm{TiO}_{2}$ nanofluid magnetohydrodynamic (MHD) flow experimentally through a mini-channel heat sink with a confined jet impingement. The effects of different magnetic fields $(B=0.084$ and $0.28 \mu \mathrm{T})$ were investigated in their work. Ashorynejad and Zarghami [22] used the lattice Boltzmann method to investigate the thermal characteristics of partially porous wavy channels using Cu nanofluid MHD (water based nanofluid) flow. Important parameters including Nusselt number, Hartmann number, pressure drop, friction factor, and Darcy number were investigated in their research. 
Dormohammadi et al. [23] studied the thermal entropy generation and characteristics of a sinusoidal wavy wall channel with a water based $\mathrm{Cu}$ nanofluid flow. The results show that the entropy generation values increase when increasing the Richardson numbers. Saeed and Kim [24] studied the thermal characteristics of a mini-channel heat sink using $\mathrm{Al}_{2} \mathrm{O}_{3}$ water based nanofluid. They analyzed the different influences of geometrical parameters, nanofluid flow velocities, and nanoparticle volume fractions on outlet temperatures and heat transfer improvements.

Dalkılıç et al. [25] investigated the thermal enhancement of different quad channel (horizontal tube) inserts filled with water based graphite- $\mathrm{SiO}_{2}$ hybrid nanofluid. In that study, convection heat transfer and the nanofluid flow were simulated in the turbulent flow regime $(3400<\operatorname{Re}<11,000)$. The results illustrated that the nanofluid can significantly improve heat transfer parameters. Saba et al. [26] investigated the usage of hybrid SWCNT$\mathrm{Fe}_{3} \mathrm{O}_{4}$ water based nanofluid for thermal efficiency improvement of an asymmetric channel with dilating or squeezing walls. They realized that the SWCNTs nanoparticles have a superior influence on thermal characteristics. Ajeel et al. [27] numerically and experimentally studied convective heat transfer and turbulent flow inside a different channel filled with $\mathrm{Al}_{2} \mathrm{O}_{3}$ water based nanofluid in the turbulent flow regime $(10,000<\operatorname{Re}<30,000)$. Based on the results, the utilization of nanofluid and corrugated geometry increases system energy efficiency. Gholami et al. [28] studied natural convection heat transfer in a vertical channel wall equipped with dimple fins filled with different nanofluids (water based $\mathrm{Al}_{2} \mathrm{O}_{3}$, $\mathrm{TiO}_{2}, \mathrm{Cu}$ and CNT nanofluids) by the finite volume method (FVM). In addition, they used the SIMPLE algorithm for pressure-velocity system coupling and governing equations discretization. They found that $\mathrm{TiO}_{2}$ nanofluid at a volume fraction of $6 \%$ had the highest thermal performance among all studied models.

Shah et al. [29] numerically studied nanofluid flow and radiative heat transfer between permeable channels. Different effects of non-dimensional parameters like Darcys Number, micropolar parameter, injection/suction fractional factor, flow velocity, radiation parameter, and Prandtl number, were analyzed in detail in their paper. Ajeel et al. [30,31] experimentally and numerically studied heat transfer in different channels by $\mathrm{SiO}_{2}$ water nanofluid. Their goal was to analyze different nanoparticle volume fractions $(1<\varphi<4 \%)$ and flow velocities $(10,000<\operatorname{Re}<30,000)$. The results showed that numerical and experimental data had fine convergence and supported each other. In another study, geometrical parameter effects investigated thermal-hydraulic performance (friction factor and average Nusselt number) in a trapezoidal channel filled with $\mathrm{SiO}_{2}$ water based nanofluid [32]. In that study, the nanofluid flow $\left(\mathrm{SiO}_{2}\right.$-graphite water based nanofluid) was simulated in a turbulent regime $(10,000<\operatorname{Re}<30,000)$ and also a house shaped-different channel. Their results indicated that the nanofluid and different geometries enhanced the energy efficiency of the system.

Our literature review indicates that the effects of different wall shapes on thermalhydraulic characteristics of different channels filled with water based graphite- $\mathrm{SiO}_{2}$ hybrid nanofluid have not yet been analyzed by researchers. In this work, the performance evaluation criteria (PEC) index is employed as a target parameter to ascertain the optimum geometry.

\section{Numerical Model}

\subsection{Physical Model}

A schematic diagram of the heat exchangers studied is shown in Figure 1. It can be seen that six different cases are studied in this paper with different wall shapes and boundary conditions. Each case has different geometrical dimensions, which are investigated numerically to achieve the most efficient configuration. The channel is under a constant temperature of $T_{S}=450 \mathrm{~K}$. The heat transfer fluid (HTF) is hybrid graphite- $\mathrm{SiO}_{2}$ water based nanofluid, which enters the channel at $330 \mathrm{~K}$ and at different flow velocities of $\operatorname{Re}=11,000,15,000,19,000$, and 23,000 (Table 1). 

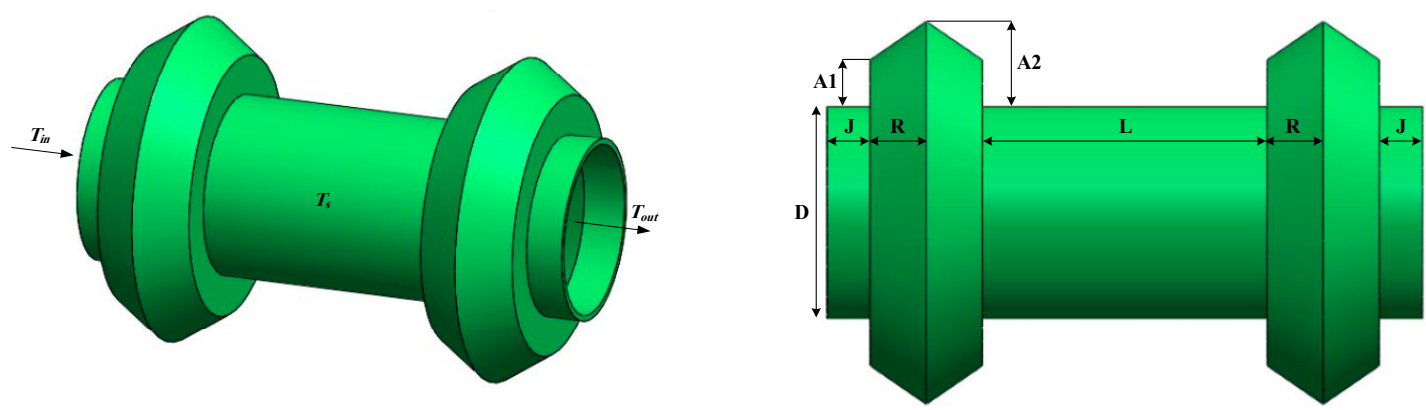

Case A
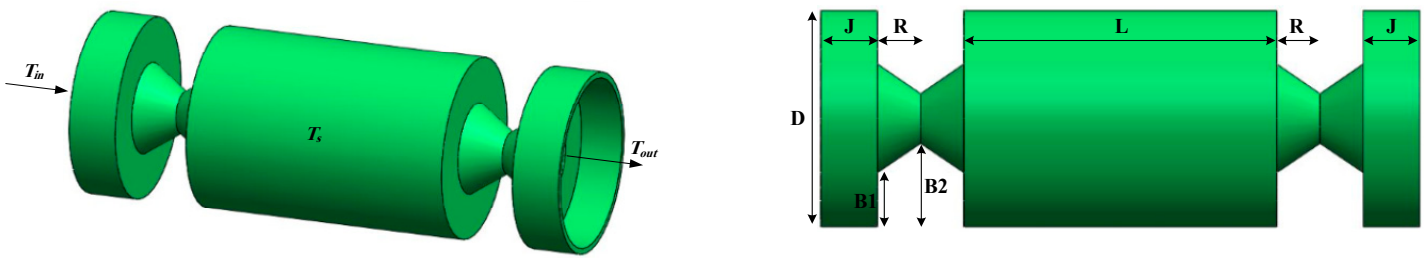

Case B
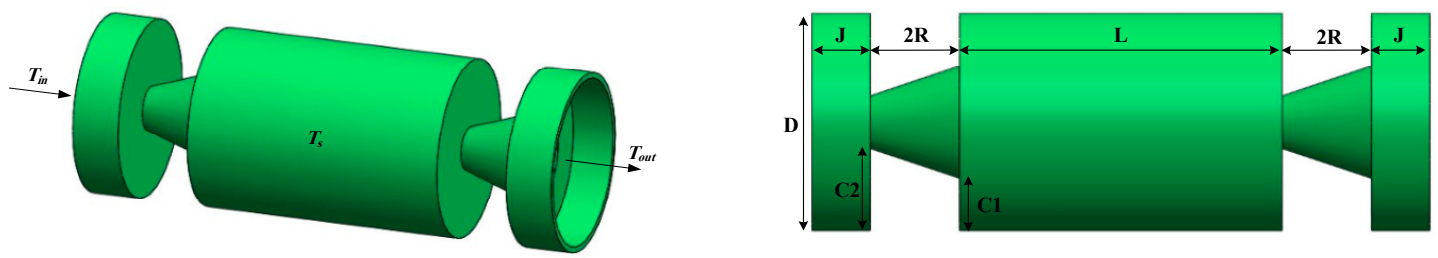

Case C
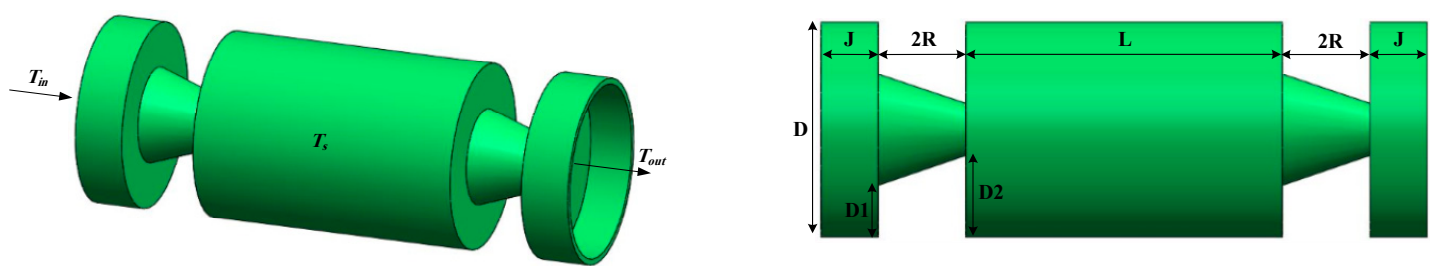

Case D
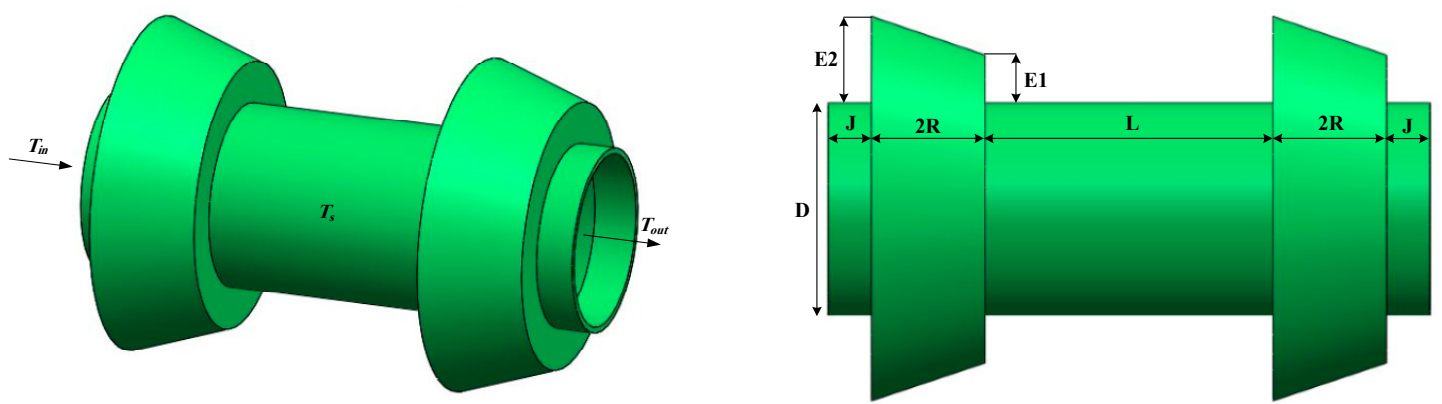

Case E
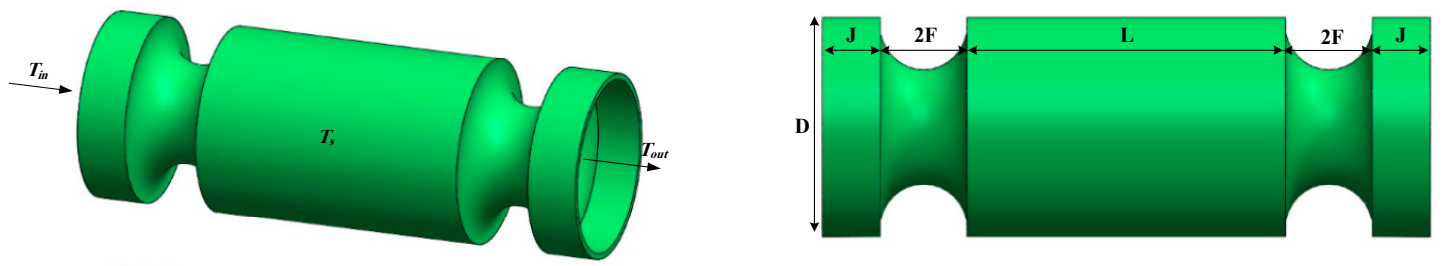

Case F

Figure 1. Schematic of heat exchangers with different wall shapes and boundary conditions. 
Table 1. Boundary conditions and geometrical data.

\begin{tabular}{cccc}
\hline Parameters & Values & Parameters & Values \\
\hline$D$ & $60 \mathrm{~mm}$ & $J$ & $17 \mathrm{~mm}$ \\
$L$ & $180-4 R-2 J$ & $R$ & 11,13 and $15 \mathrm{~mm}$ \\
$A 1$ & $12 \mathrm{~mm}$ & $A 2$ & 22,24 and $26 \mathrm{~mm}$ \\
$B 1$ & $12 \mathrm{~mm}$ & $B 2$ & 22,24 and $26 \mathrm{~mm}$ \\
$C 1$ & $12 \mathrm{~mm}$ & $C 2$ & 22,24 and $26 \mathrm{~mm}$ \\
$D 1$ & $12 \mathrm{~mm}$ & $D 2$ & 22,24 and $26 \mathrm{~mm}$ \\
$E 1$ & $12 \mathrm{~mm}$ & $E 2$ & 10,12 and $14 \mathrm{~mm}$ \\
$F$ & $11,13 \mathrm{and} 15 \mathrm{~mm}$ & $\delta$ & $2 \mathrm{~mm}$ \\
$T_{\text {in }}$ & $330 \mathrm{~K}$ & $T_{S}$ & $450 \mathrm{~K}$ \\
$P_{\text {out }}$ & 0 (gage) & Re & $11,000,15,000,19,000$, \\
\end{tabular}

Table 2 presents the thermophysical properties of the base fluid and nanoparticles.

Table 2. Thermophysical properties of base fluid and nanoparticles [25].

\begin{tabular}{|c|c|c|c|c|}
\hline $\begin{array}{c}\text { Thermophysical } \\
\text { Properties }\end{array}$ & $k(\mathrm{~W} / \mathrm{m} \cdot \mathrm{K})$ & $c_{p}(\mathrm{~J} / \mathrm{kg} \cdot \mathrm{K})$ & $\rho\left(\mathrm{kg} / \mathrm{m}^{3}\right)$ & $\begin{array}{l}\text { Mean Diameter } \\
\text { of Particle (nm) }\end{array}$ \\
\hline Graphite & 25 & 720 & 2060 & 8 \\
\hline $\mathrm{SiO}_{2}$ & 1.4 & 765 & 2200 & 7 \\
\hline water & 0.613 & 4179 & 997.1 & - \\
\hline
\end{tabular}

The hybrid nanoparticle volume fraction based on the proportion of $\mathrm{SiO}_{2}$ and graphite nanoparticle portions is calculated using the following equation [25]:

$$
\varphi=\left[\frac{\left(\frac{m_{n p 1}}{\rho_{n p 1}}\right)+\left(\frac{m_{n p 2}}{\rho_{n p 2}}\right)}{\left(\frac{m_{n p 1}}{\rho_{n p 1}}\right)+\left(\frac{m_{n p 2}}{\rho_{n p 2}}\right)+\left(\frac{m_{b f}}{\rho_{b f}}\right)}\right]
$$

where $m$ is the mass portion of used materials

The hybrid nanofluid density can be written as followss [5]:

$$
\rho_{n f}=\varphi_{n p 1} \rho_{n p 1}+\varphi_{n p 2} \rho_{n p 2}+\left(1-\varphi_{n p 1}-\varphi_{n p 2}\right) \rho_{b f}
$$

where $\varphi_{n p 1}$ and $\varphi_{n p 2}$ are the nanoparticle volume fractions of $\mathrm{SiO}_{2}$ and Graphite, respectively [25].

The hybrid nanofluid specific heat capacity is calculated using the following Equation [25]:

$$
\left(\rho_{n f} \times c_{p, n f}\right)=\varphi_{n p 1} \rho_{n p 1} c_{p, n p 1}+\varphi_{n p 2} \rho_{n p 2} c_{p, n p 2}+\left(1-\varphi_{n p 1} \rho_{n p 1}-\varphi_{n p 2} \rho_{n p 2}\right) c_{p, b f}
$$

The hybrid nanofluid relative dynamic viscosity can be written as follows [25]:

$$
\frac{\mu_{n f}}{\mu_{b f}}=1.00527 \times T^{0.00035} \times(1+\varphi)^{9.36265} \times\left(\frac{m_{n p 1}}{m_{n p 2}}\right)^{-0.028935}
$$

where $T$ is the average temperature.

The hybrid nanofluid relative thermal conductivity is determined as follows [25]:

$$
\frac{k_{n f}}{k_{b f}}=0.852870218 \times T^{0.052797513} \times(1+\varphi)^{6.591412917} \times\left(\frac{m_{n p 2}}{m_{n p 1}}\right)^{0.022254808}
$$

\subsection{Governing Equations}

In this work, the Eulerian-Eulerian (two-phase technique) was used to simulate the nanofluid in channel. The continuity equation and momentum are also reported 
using the following equations [33-36], where the mixture dynamic viscosity is $\mu_{m}$, the pressure is $\vec{P}$, the density of the two-phase mixture is $\rho_{m}$, the base fluid velocity is $\vec{U}_{b f}$, the nanoparticle velocity is $\vec{U}_{s}$, and the base fluid and nanoparticles velocities are $\vec{U}_{d r, b f}$ and $\vec{U}_{d r, s}$, respectively [36].

Continuity equation:

$$
\nabla\left(\rho_{n f}\left(\frac{\rho_{s} \phi_{s} \vec{U}_{s}+\rho_{b f} \phi_{b f} \vec{U}_{b f}}{\rho_{s} \phi_{s}+\rho_{b f} \phi_{b f}}\right)\right)=0
$$

Momentum equation:

$$
\begin{aligned}
\rho_{n f}\left(\vec{U}_{m} \nabla \vec{U}_{m}\right)=-\nabla \vec{P}+\mu_{m}\left(\nabla \vec{U}_{m}+\right. & \left.\left(\nabla \vec{U}_{m}\right)^{T}\right)+\nabla\left(\rho_{b f} \phi_{b f} \vec{U}_{d r, b f} \vec{U}_{d r, b f}+\rho_{s} \phi_{s} \vec{U}_{d r, s} \vec{U}_{d r, s}\right)+\rho_{m} \vec{g} \\
& \vec{U}_{d r, b f}=\vec{U}_{b f}-\vec{U}_{m} \\
\vec{U}_{d r, s}= & \vec{U}_{s}-\vec{U}_{m}
\end{aligned}
$$

The energy equation is reported here, where the enthalpy of solid particles and the base fluid are $h_{s}$ and $h_{b f}$, respectively. The equation of volume fraction for slip velocity and two-phase mixture are defined by Refs. $[37,38]$. These equations are suitable to calculate the relation between drift velocity and relative velocity $[39,40]$. The nanoparticle Reynolds number $\left(\operatorname{Re}_{s}\right)$ is also offered, where $d_{p}$ is the mean particle diameter. The relative velocity is calculated from Schiller and Naumann's formulation, where the gravitational acceleration of the fluid and the nanoparticle are $\vec{g}$ and $\vec{\alpha}$, respectively [41].

Energy equation:

$$
\begin{gathered}
\nabla\left(\rho_{b f} \phi_{b f} \vec{U}_{b f} h_{b f}+\rho_{s} \phi_{s} \vec{U}_{s} h_{s}\right)=\nabla\left(\left(\phi_{b f} k_{b f}+\phi_{s} k_{s}\right) \nabla \vec{T}\right) \\
\nabla\left(\rho_{s} \phi_{s} \vec{U}_{m}\right)=-\nabla\left(\rho_{s} \phi_{s} \vec{U}_{d r, s}\right) \quad \vec{U}_{b f, s}=\vec{U}_{b f}-\vec{U}_{s} \quad \vec{U}_{d r, s}=\vec{U}_{s, b f}-\frac{\rho_{s} \phi_{s}}{\rho_{m}} \vec{U}_{b f, s} \\
\vec{U}_{b f, s}=\frac{d_{p}^{2}}{18 \mu_{b f} f_{d}} \frac{\rho_{s}-\rho_{m}}{\rho_{s}} \vec{\alpha} \quad f_{d}=1+0.15 \operatorname{Re}_{s}^{0.687} \\
\vec{\alpha}=\vec{g}-\left(\vec{U}_{m} \nabla \vec{U}_{m}\right) \quad \operatorname{Re}_{s}=\frac{\vec{U}_{m} d_{p} \rho_{m}}{\mu_{m}}
\end{gathered}
$$

Equation (9) presents the descriptive equations of the k- $\varepsilon$ model, where $\mu_{t, m}$ is the turbulent dynamic viscosity and $k, G$ are production rates [37-39]. Additionally, $\mathrm{Nu}_{r}$ and $f_{r}$ are the ratios between the reference system and the novel configurations. The reference configuration ( $\mathrm{RC}$ ) is the empty test section (without twisted tape) filled with nanofluid at $0.2 \%$ volume concentration. The standard constants are employed, $C_{\mu}=0.09, c_{1}=1.44$, $c_{2}=1.92, \sigma_{k}=1.00, \sigma_{\varepsilon}=1.30$, and $\sigma_{t}=0.85$. The Nusselt number and Rayleigh number of the nanofluid are also reported in [33-37].

Turbulence equations:

$$
\begin{gathered}
\nabla\left(\rho_{m} \vec{U}_{m} k\right)=\nabla\left[\left(\mu_{m}+\frac{\mu_{t, m}}{\sigma_{k}}\right) \nabla k\right]+G_{k, m}-\rho_{m} \varepsilon \\
\nabla\left(\rho_{m} \vec{U}_{m} \varepsilon\right)=\nabla\left[\left(\mu_{m}+\frac{\mu_{t, m}}{\sigma_{\varepsilon}}\right) \nabla \varepsilon\right]+\frac{\varepsilon}{k}\left(c_{1} G_{k, m}-c_{2} \rho_{m} \varepsilon\right) \\
\mu_{t, m}=C_{\mu} \rho_{m} \frac{k^{2}}{\varepsilon} \quad G_{k, m}=\mu_{t, m}\left(\nabla \vec{U}_{m}+\left(\nabla \vec{U}_{m}\right)^{T}\right)
\end{gathered}
$$

Average Nusselt number:

$$
N u=\frac{k_{n f}}{k_{f}} \int \frac{\partial T}{\partial x}
$$

Nusselt number ratio:

$$
N u_{r}=\frac{N u}{N u_{0}}
$$


Mean friction factor:

$$
f=\frac{2 D_{h}}{L} \frac{\Delta P}{\rho_{n f} V_{i n}^{2}}
$$

Friction factor ratio:

$$
f_{r}=\frac{f}{f_{0}}
$$

Performance evaluation criteria index:

$$
\mathrm{PEC}=N u_{r} \cdot f_{r}^{-\frac{1}{3}}
$$

\subsection{Grid Mesh Independence Test}

The grid mesh independence test was done in this research to achieve the most efficient grid mesh layout with the minimum error (4\%) and calculating time (see Figure 2). Different grid meshes were analyzed, and error values were achieved in Nusselt number terms. Finally, the grid mesh with 2478 nodes was adopted as the valuable grid mesh for numerical simulation.

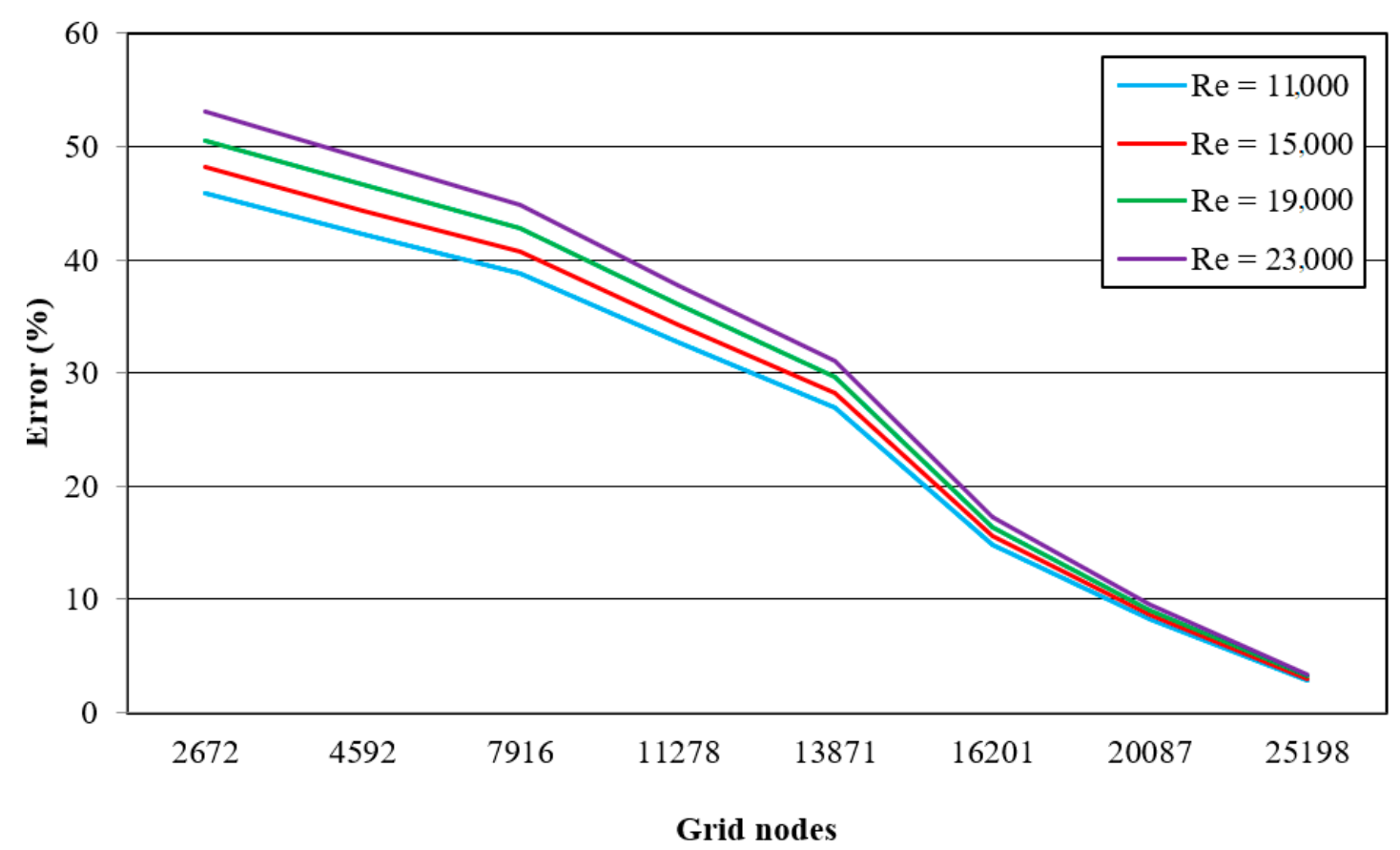

Figure 2. The grid mesh independence test in different Reynolds numbers.

\subsection{Validation}

Figure 3 shows the code validation between the numerical data of Yang and Ordonez [42] and the obtained numerical results from the current study in the case of the PEC index. The PEC numbers were compared at similar geometries and boundary conditions. As can be seen in Figure 3, there is remarkable uniformity between the numerical data of Yang and Ordonez [42] and the numerical results obtained from the current study. 


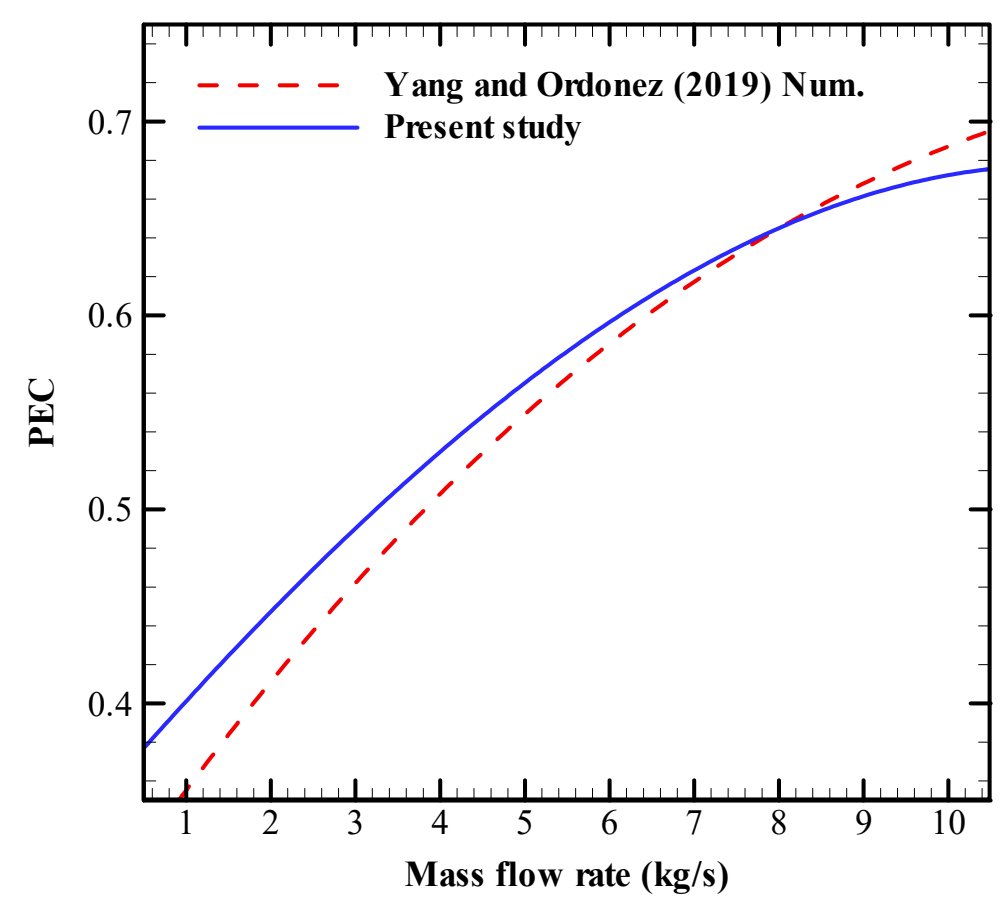

Figure 3. Code validation between numerical data of Yang and Ordonez [42] and obtained numerical results from the current study in case of PEC index.

\section{Results and Discussion}

In this section, the results of the numerical simulations for different configurations with different geometric parameters are examined. The numerical results of the temperature contour, velocity contour, streamlines, kinetic energy contour, Nusselt number variation, friction factor, and PEC index are presented. In the end, different configurations are compared and arranged in terms of PEC.

\subsection{Case A}

In Case $\mathrm{A}$, two parameters are variable, which are $R$ and $A 2$. First, the variations in the $R$ parameter are examined and then parameter $A 2$ is analyzed. Therefore, here streamlines, velocity, kinetic energy contours, and temperature are used. Figure 4 shows streamlines for various configurations of Case A with different $R$ parameters at $A 2=24 \mathrm{~mm}$, $\operatorname{Re}=15,000$, and $\varphi=0.5 \%$. As can be seen, by changing parameter $R$, the streamlines are affected and change. As parameter $R$ becomes smaller, the formation of vortices and local turbulence in the pipe increases and the flow mixing rate increases. This, on the one hand, increases the heat transfer coefficient, and on the other hand, leads to a greater pressure drop penalty. This can clearly be seen by the reduction in the dark blue color in this section of the tube. Figure 5 illustrates temperature contours for various configurations of Case A with different $R$ parameters at $A 2=24 \mathrm{~mm}, \operatorname{Re}=15,000$, and $\varphi=0.5 \%$. As can be seen, by changing parameter $R$, the temperature contours are affected and change. As parameter $R$ becomes smaller, a reduction in the dark blue color in this section of the tube can be seen. The presence of sharp edges in this geometry causes the separation and reversal of the flow, which decreases parameter $R$ and increases parameter $A 2$. The main reason for the formation of the vortex is exactly these sharp edges. 


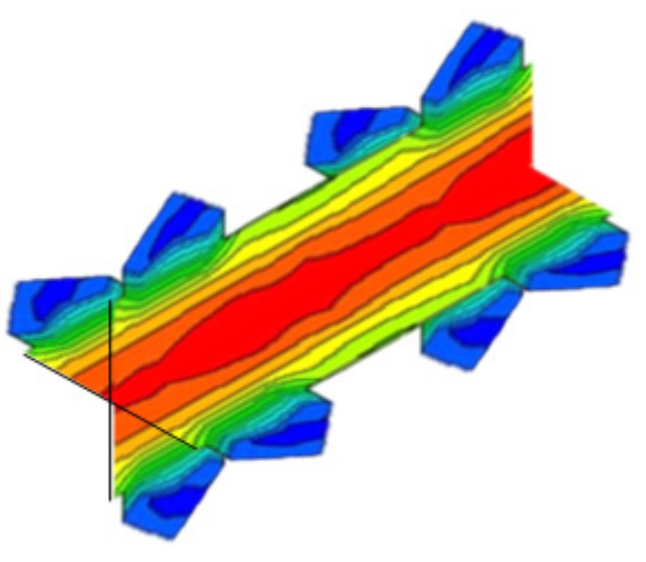

(a) $\mathrm{R}=15 \mathrm{~mm}$

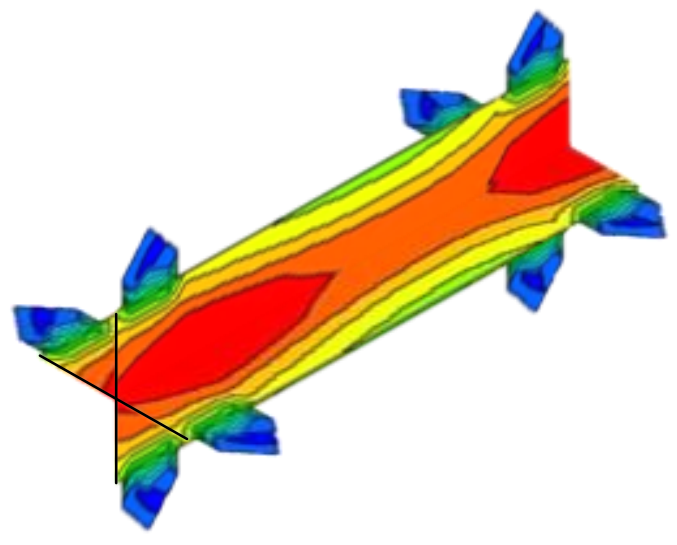

(c) $\mathrm{R}=11 \mathrm{~mm}$

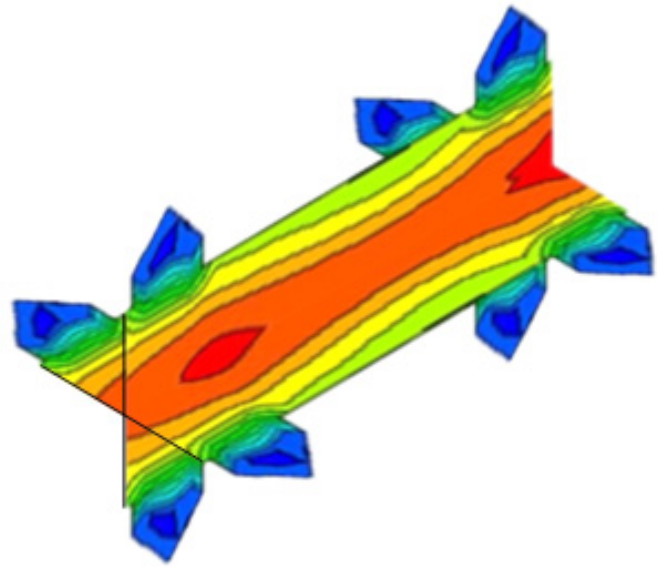

(b) $\mathrm{R}=13 \mathrm{~mm}$

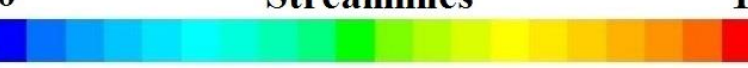

Figure 4. Streamlines for various configurations of Case A with different $R$ parameters at $A 2=24 \mathrm{~mm}, \operatorname{Re}=15,000$, and $\varphi=0.5 \%$.

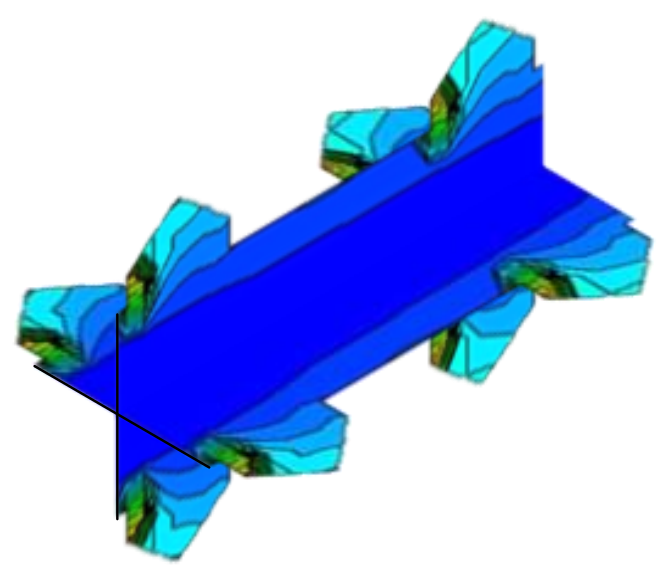

(a) $\mathrm{R}=15 \mathrm{~mm}$

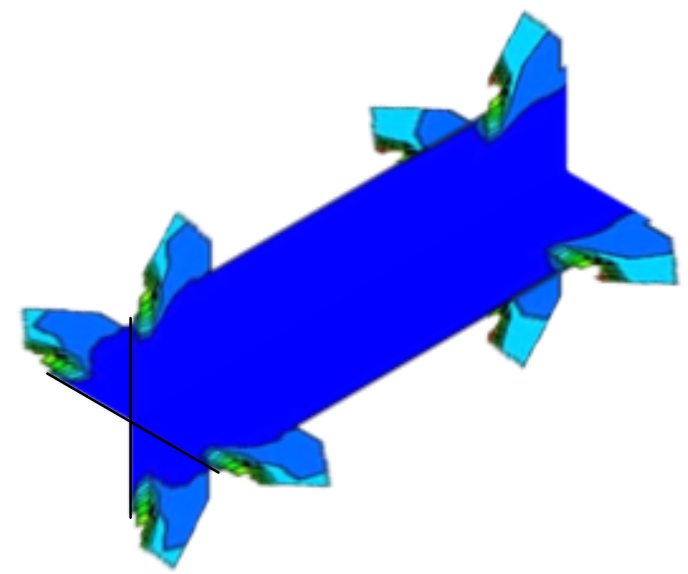

(b) $\mathrm{R}=13 \mathrm{~mm}$

Figure 5. Cont. 


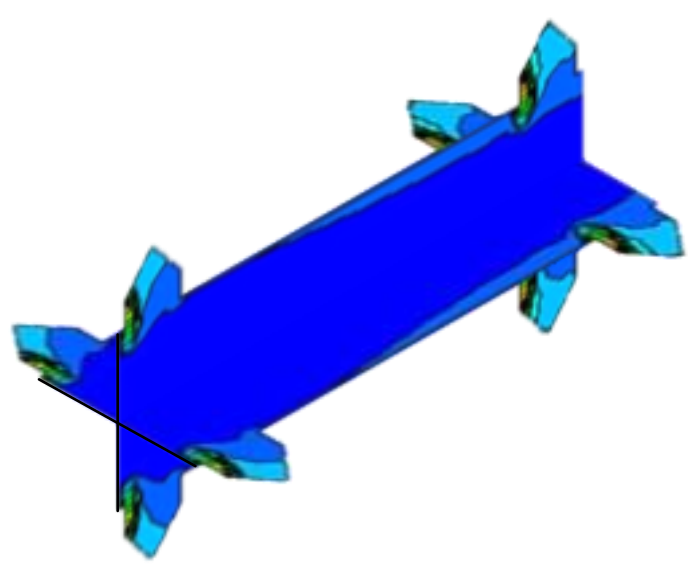

(c) $\mathrm{R}=11 \mathrm{~mm}$
0 Temperature contour 1

Figure 5. Temperature contours for various configurations of Case A with different $R$ parameters at $A 2=24 \mathrm{~mm}, \operatorname{Re}=15,000$, and $\varphi=0.5 \%$.

Figure 6 presents kinetic energy contours for various configurations of Case A with different $R$ parameters at $A 2=24 \mathrm{~mm}, \operatorname{Re}=15,000$, and $\varphi=0.5 \%$. A reduction in light green and blue colors with a reduction of parameter $R$ is observed in these figures. Figure 7 demonstrates velocity magnitude contours for various configurations of Case A with different $R$ parameters at $A 2=24 \mathrm{~mm}, \operatorname{Re}=15,000$, and $\varphi=0.5 \%$. This can clearly be seen in the reduction in the dark blue color in this section of the tube with a reduction in parameter $R$.

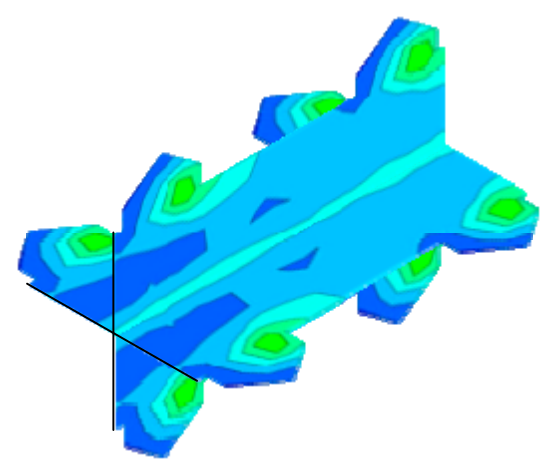

(a) $\mathrm{R}=15 \mathrm{~mm}$

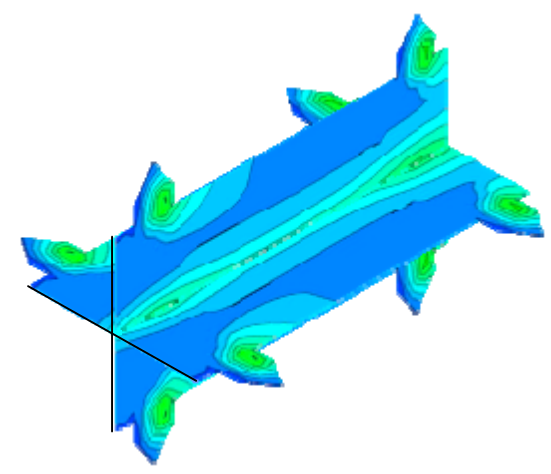

(c) $\mathrm{R}=11 \mathrm{~mm}$

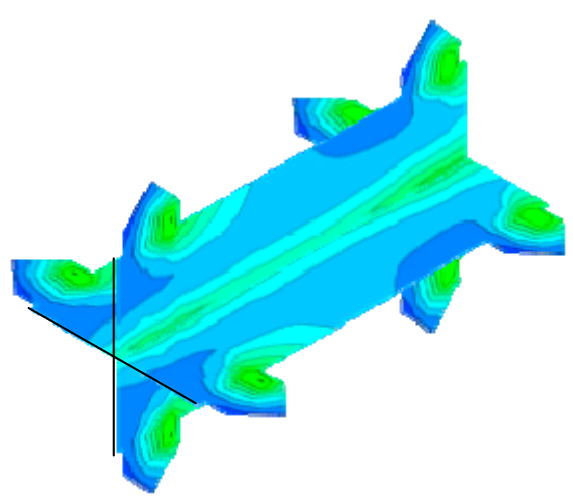

(b) $\mathrm{R}=13 \mathrm{~mm}$

\section{0} $0 \quad$ Kinetic energy contour

Color map

Figure 6. Kinetic energy contours for various configurations of Case A with different $R$ parameters at $A 2=24 \mathrm{~mm}$, $\operatorname{Re}=15,000$, and $\varphi=0.5 \%$. 


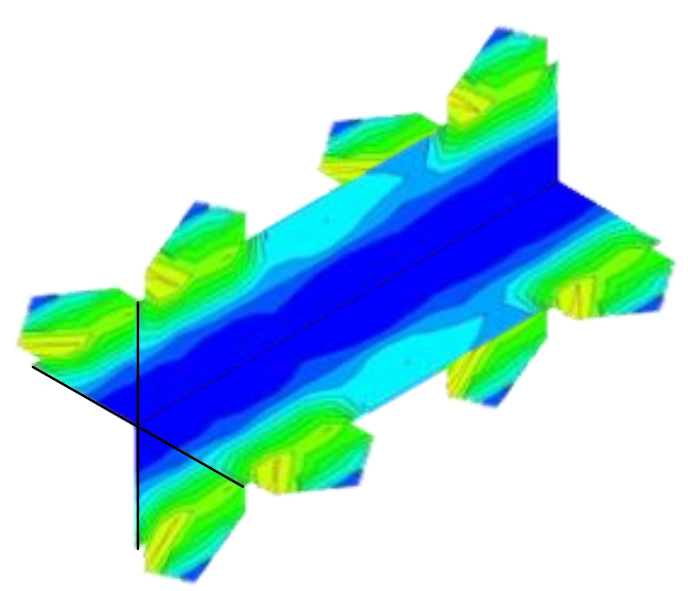

(a) $\mathrm{R}=15 \mathrm{~mm}$

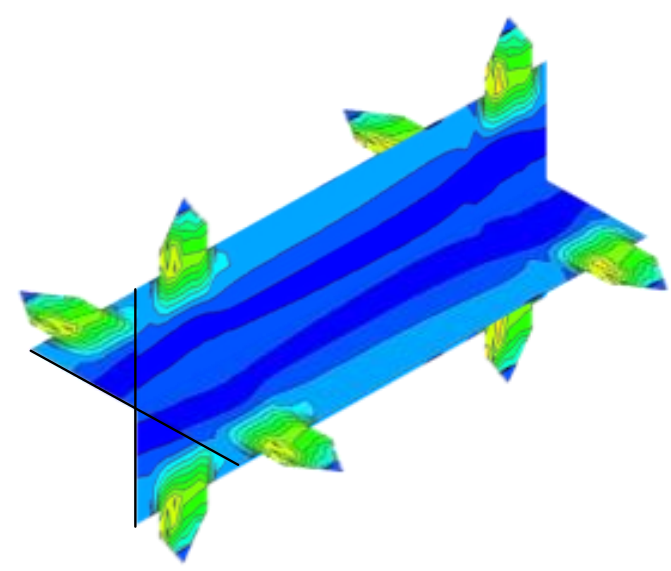

(c) $\mathrm{R}=11 \mathrm{~mm}$

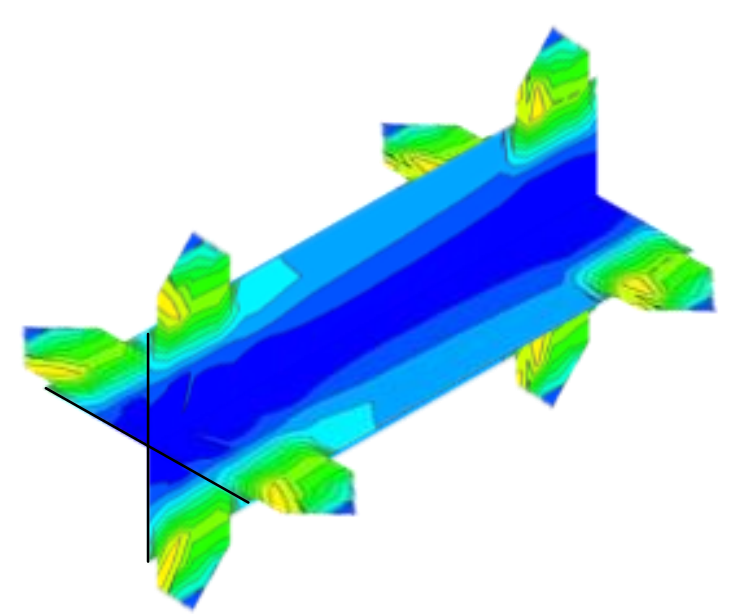

(b) $\mathrm{R}=13 \mathrm{~mm}$

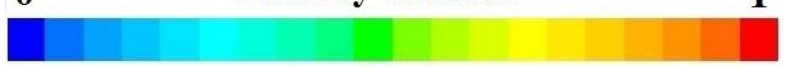

Color map

Figure 7. Velocity magnitude contours for various configurations of Case A with different $R$ parameters at $A 2=24 \mathrm{~mm}$, $\operatorname{Re}=15,000$, and $\varphi=0.5 \%$.

However, in order to reduce the volume of the article, contours related to different Reynolds numbers have been omitted. As can be seen, increasing the Reynolds number intensifies the turbulence, increases the flow mixing rate, and increases the vortices. This leads to an increase in heat transfer coefficient as well as an increase in the pressure drop penalty.

Figure 8 shows streamlines for various configurations of Case A with different $A 2$ parameters at $R=15 \mathrm{~mm}, \operatorname{Re}=15,000$, and $\varphi=0.5 \%$. As can be seen, by changing parameter $A 2$, the streamlines are affected and change. As parameter $A 2$ becomes longer, the formation of vortices and local turbulence in the pipe increases and the flow mixing rate increases. This, on the one hand, increases the heat transfer coefficient, and on the other hand, leads to a greater pressure drop penalty. This can clearly be seen by the reduction in the dark blue color in this section of the tube. 


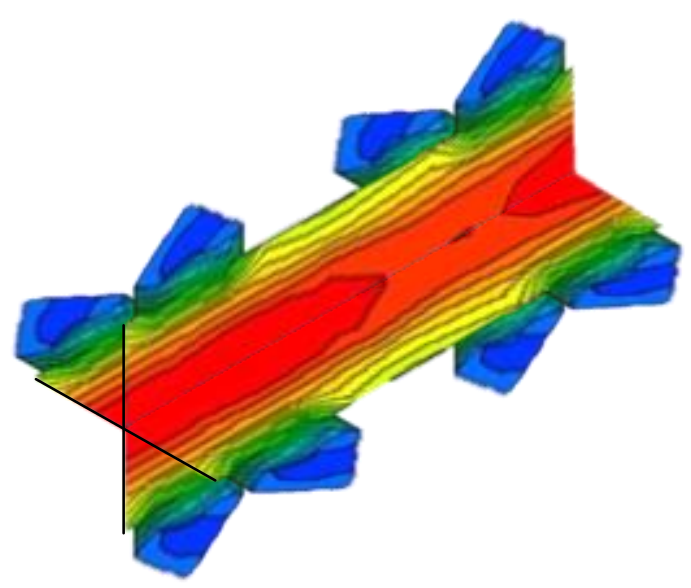

(a) $\mathrm{A}_{2}=26 \mathrm{~mm}$

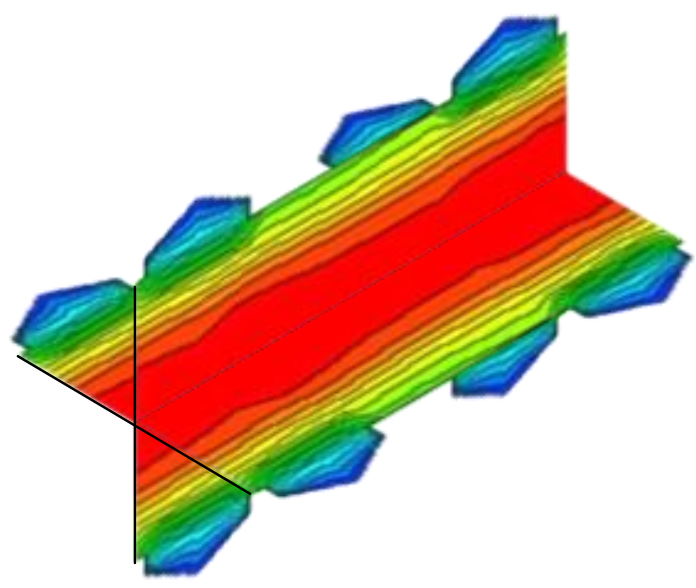

(c) $\mathrm{A}_{2}=22 \mathrm{~mm}$

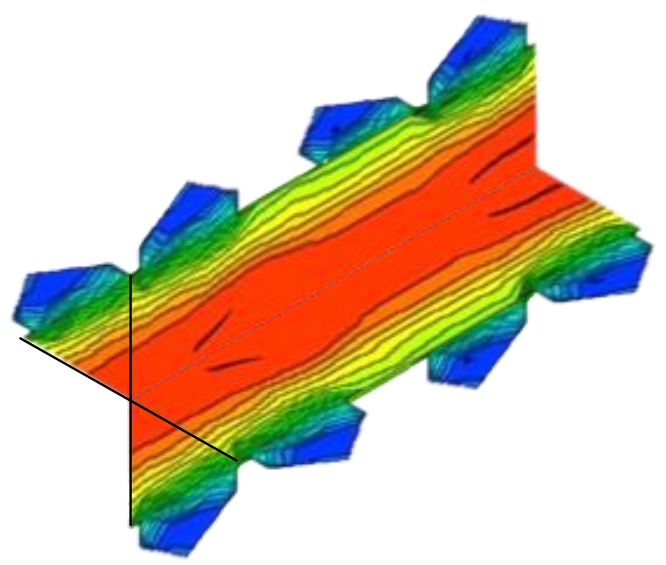

(b) $\mathrm{A}_{2}=24 \mathrm{~mm}$

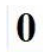

0

Color map

Figure 8. Streamlines for various configurations of Case A with different $A 2$ parameters at $R=15 \mathrm{~mm}, \operatorname{Re}=15,000$, and $\varphi=0.5 \%$.

Figure 9 illustrates temperature contours for various configurations of Case A with different $A 2$ parameters at $R=15 \mathrm{~mm}, \operatorname{Re}=15,000$, and $\varphi=0.5 \%$. As can be seen, by changing parameter $A 2$, the temperature contours are affected and change. As parameter $A 2$ becomes longer, a reduction in the dark blue color in this section of the tube can be seen. Figure 10 presents kinetic energy contours for various configurations of Case A with different $A 2$ parameters at $R=15 \mathrm{~mm}, \operatorname{Re}=15,000$, and $\varphi=0.5 \%$. A reduction in light green and blue colors with a reduction in parameter $R$ is observed in these figures. The presence of sharp edges in this geometry causes the separation and reversal of the flow, which decreases parameter $R$ and increases parameter $A 2$. The main reason for the formation of the vortex is exactly these sharp edges. Figure 11 demonstrates velocity magnitude contours for various configurations of Case A with different $A 2$ parameters at $R=15 \mathrm{~mm}$, $\operatorname{Re}=15,000$, and $\varphi=0.5 \%$. This can clearly be seen by the reduction in the dark blue color in this section of the tube with a reduction in parameter $R$. However, in order to reduce the volume of the article, contours related to different Reynolds numbers have been omitted. As can be seen, increasing the Reynolds number intensifies the turbulence, increases the flow mixing rate, and increases the vortices. This leads to an increase in heat transfer coefficient as well as an increase in the pressure drop penalty. 


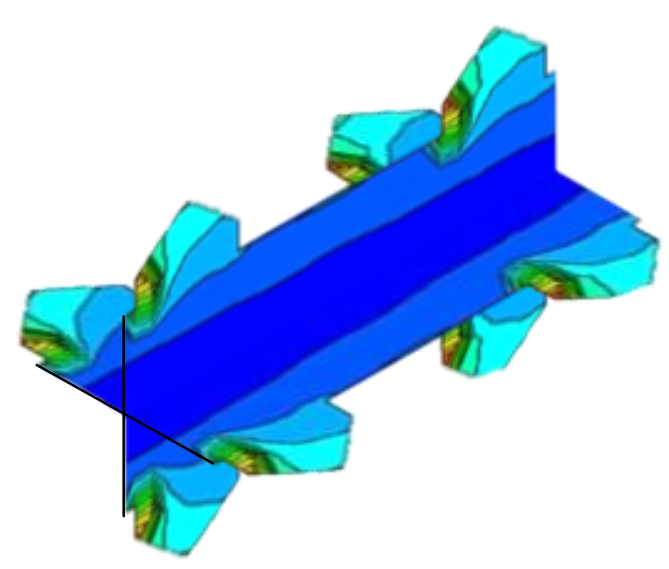

(a) $\mathrm{A}_{2}=26 \mathrm{~mm}$

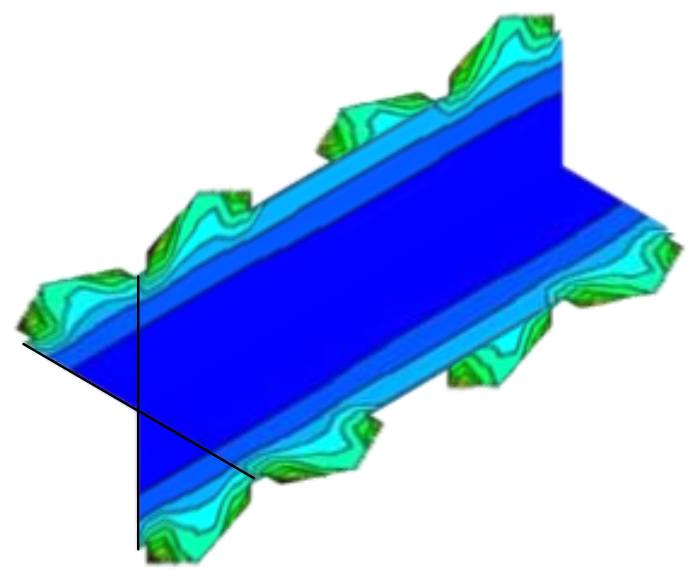

(c) $\mathrm{A}_{2}=22 \mathrm{~mm}$

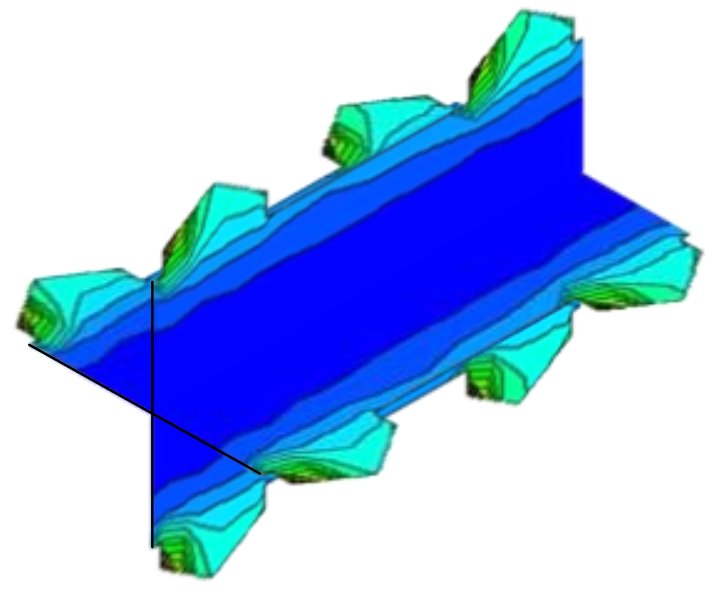

(b) $\mathrm{A}_{2}=24 \mathrm{~mm}$

0

\section{Temperature contour}

1

Figure 9. Temperature contours for various configurations of Case A with different $A 2$ parameters at $R=15 \mathrm{~mm}, \operatorname{Re}=15,000$, and $\varphi=0.5 \%$.

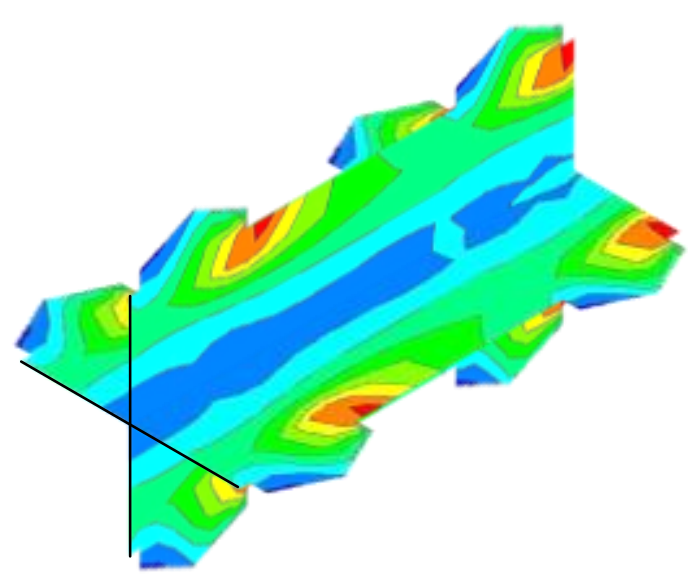

(a) $\mathrm{A}_{2}=26 \mathrm{~mm}$

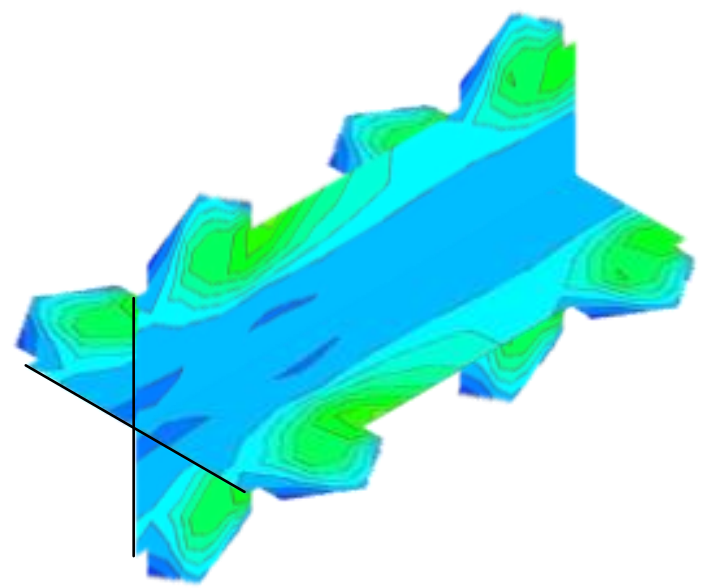

(b) $\mathrm{A}_{2}=24 \mathrm{~mm}$

Figure 10. Cont. 


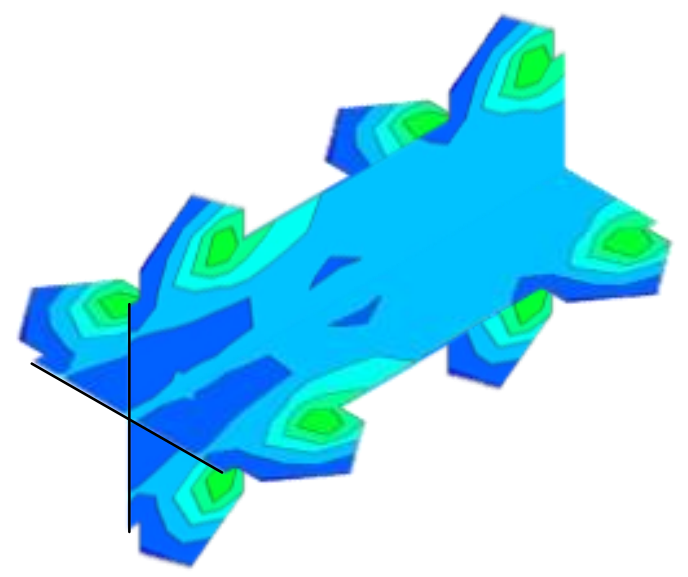

(c) $\mathrm{A}_{2}=22 \mathrm{~mm}$

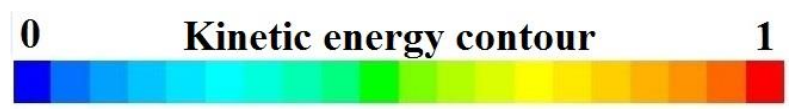

Color map

Figure 10. Kinetic energy contours for various configurations of Case A with different $A 2$ parameters at $R=15 \mathrm{~mm}$, $\operatorname{Re}=15,000$, and $\varphi=0.5 \%$.

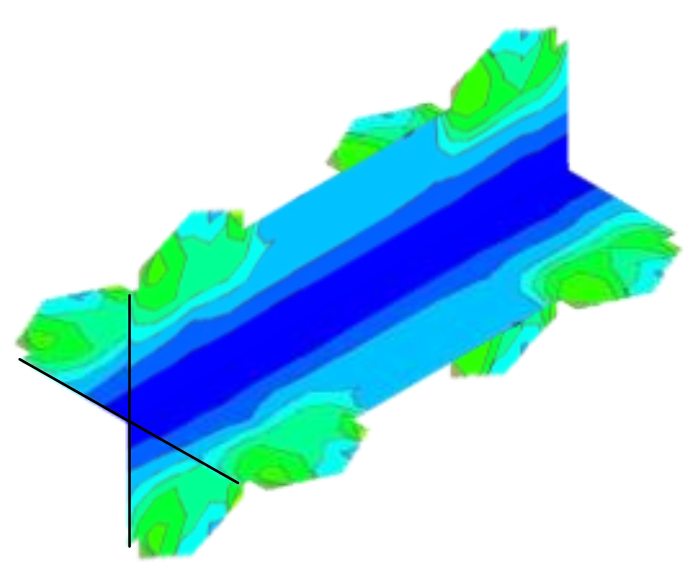

(a) $\mathrm{A}_{2}=26 \mathrm{~mm}$

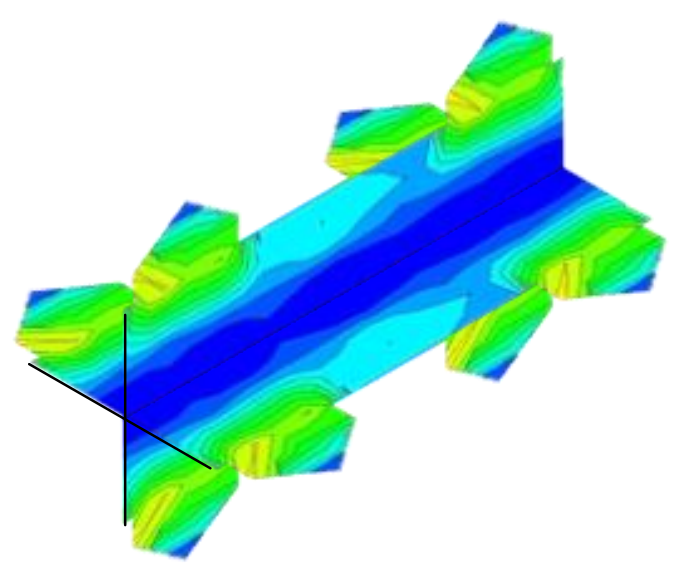

(c) $\mathrm{A}_{2}=22 \mathrm{~mm}$

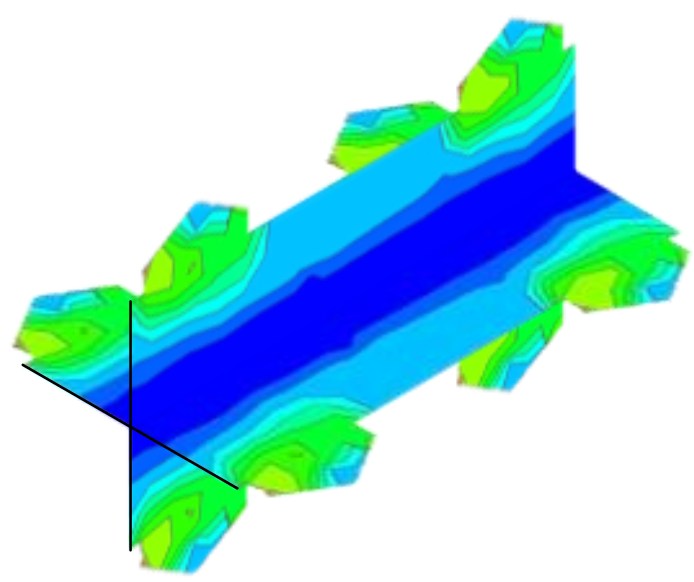

(b) $\mathrm{A}_{2}=24 \mathrm{~mm}$

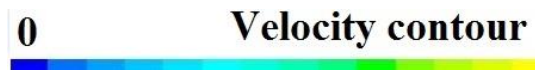

1

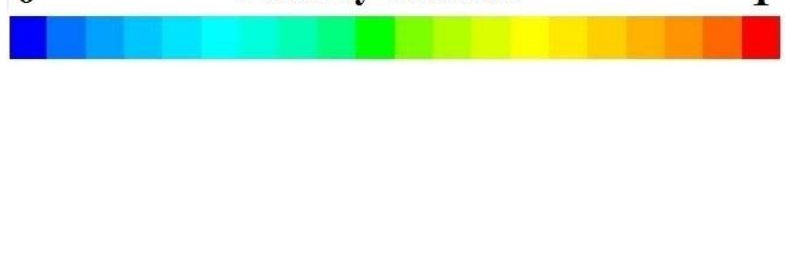
$\operatorname{Re}=15,000$, and $\varphi=0.5 \%$.

\section{Color map}

Figure 11. Velocity magnitude contours for various configurations of Case A with different $A 2$ parameters at $R=15 \mathrm{~mm}$, 


\subsection{Case $B$}

In Case B, two parameters are variable, which are $R$ and $B 2$. First, the variations in the $R$ parameter are examined and then parameter $B 2$ is analyzed. Figure 12 shows streamlines for various configurations of Case $B$ with different $R$ parameters at $B 2=24 \mathrm{~mm}, \operatorname{Re}=15,000$, and $\varphi=0.5 \%$. As can be seen, when changing parameter $R$, the streamlines are affected and thus also change. As parameter $R$ becomes smaller, the formation of vortices and local turbulence in the pipe increases and the flow mixing rate increases. This, on the one hand, increases the heat transfer coefficient, and on the other hand, leads to a greater pressure drop penalty. This can clearly be seen by the reduction in the dark blue color in this section of the tube. Figure 13 illustrates temperature contours for various configurations of Case B with different $R$ parameters at $B 2=24 \mathrm{~mm}, \operatorname{Re}=15,000$, and $\varphi=0.5 \%$. As can be seen, by changing parameter $R$, the temperature contours are affected and change. As parameter $R$ becomes smaller, a reduction in the dark blue color in this section of the tube can be seen. The presence of sharp edges in this geometry causes the separation and reversal of the flow, which decreases parameter $R$ and increases parameter $B 2$. The main reason for the formation of the vortex is exactly these sharp edges. Figure 14 presents kinetic energy contours for various configurations of Case $B$ with different $R$ parameters at $B 2=24 \mathrm{~mm}$, $\operatorname{Re}=15,000$, and $\varphi=0.5 \%$. A reduction in light green and blue colors alongside a reduction in parameter $R$ is observed in these figures. Figure 15 demonstrates velocity magnitude contours for various configurations of Case A with different $R$ parameters at $B 2=24 \mathrm{~mm}$, $\operatorname{Re}=15,000$, and $\varphi=0.5 \%$. This can clearly be seen by the reduction in the dark blue color in this section of the tube alongside a reduction in parameter $R$. However, in order to reduce the volume of the article, contours related to different Reynolds numbers have been omitted. As can be seen, increasing the Reynolds number intensifies the turbulence, increases the flow mixing rate, and increases the vortices. This leads to an increase in heat transfer coefficient as well as an increase in the pressure drop penalty.

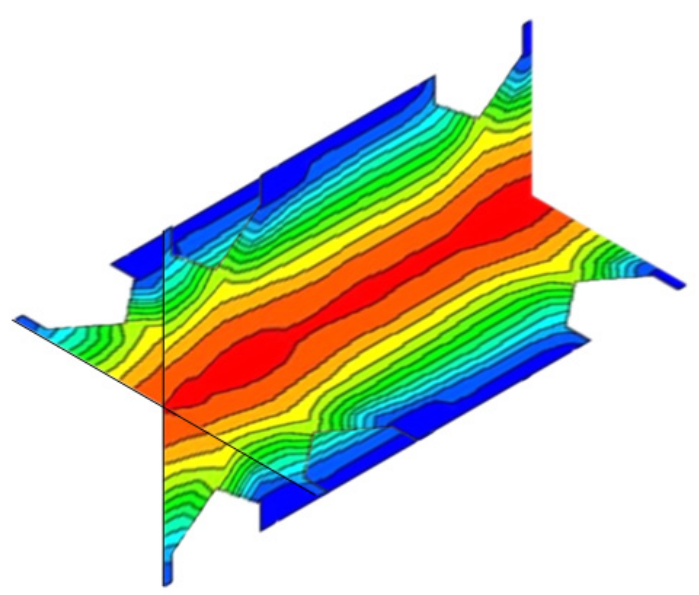

(a) $\mathrm{R}=15 \mathrm{~mm}$

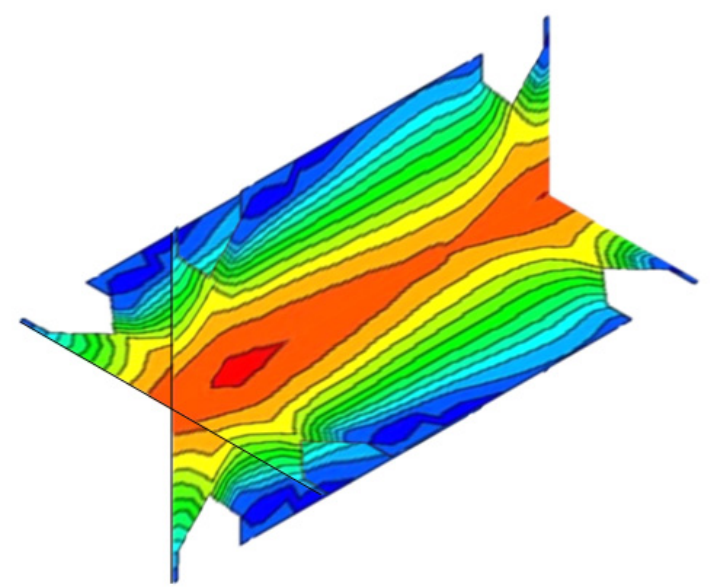

(b) $\mathrm{R}=13 \mathrm{~mm}$

Figure 12. Cont. 


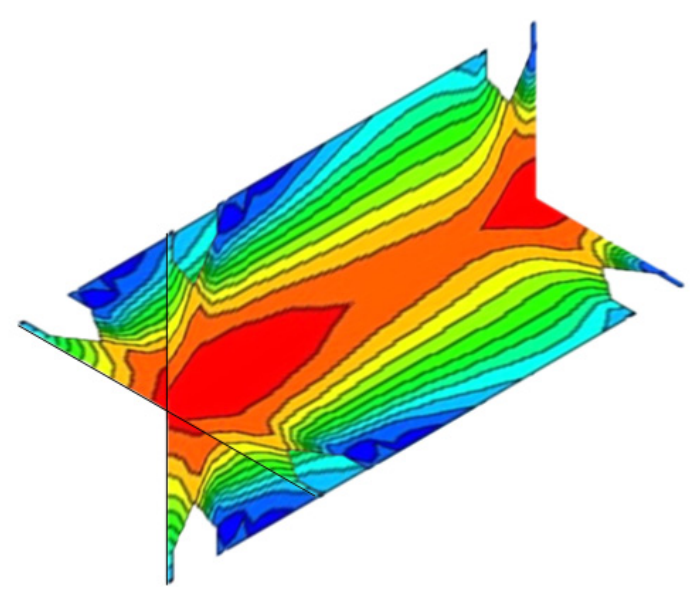

(c) $\mathrm{R}=11 \mathrm{~mm}$

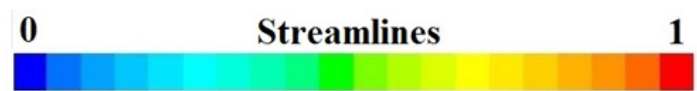

Color map

Figure 12. Streamlines for various configurations of Case B with different $R$ parameters at $B 2=24 \mathrm{~mm}, \operatorname{Re}=15,000$, and $\varphi=0.5 \%$.

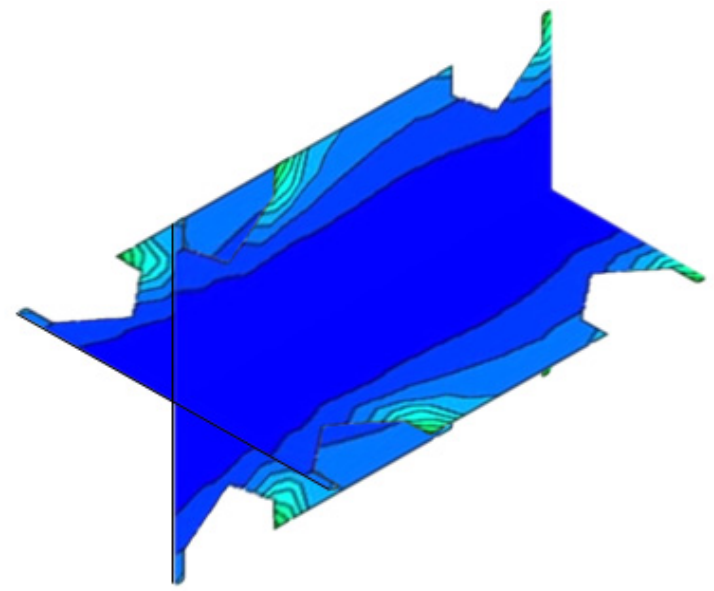

(a) $\mathrm{R}=15 \mathrm{~mm}$

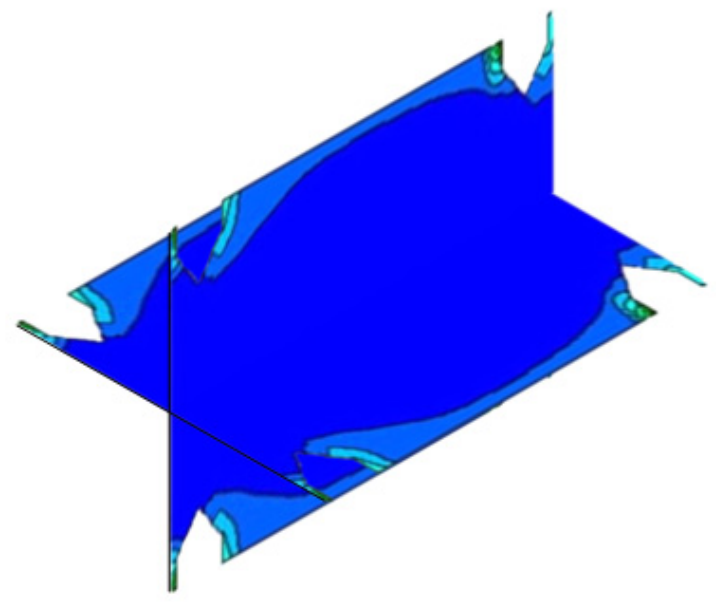

(c) $\mathrm{R}=11 \mathrm{~mm}$

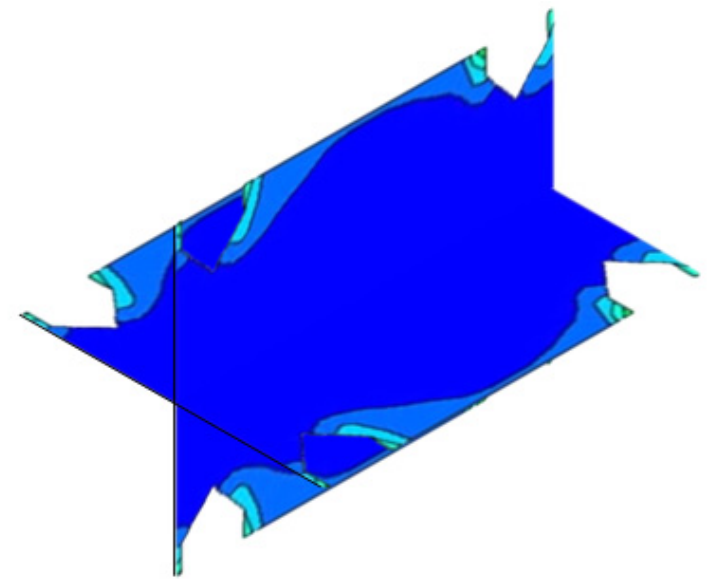

(b) $\mathrm{R}=13 \mathrm{~mm}$

\section{Temperature contour 1}

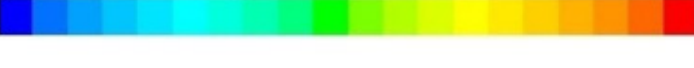

Figure 13. Temperature contours for various configurations of Case $B$ with different $R$ parameters at $B 2=24 \mathrm{~mm}, \operatorname{Re}=15,000$, and $\varphi=0.5 \%$. 


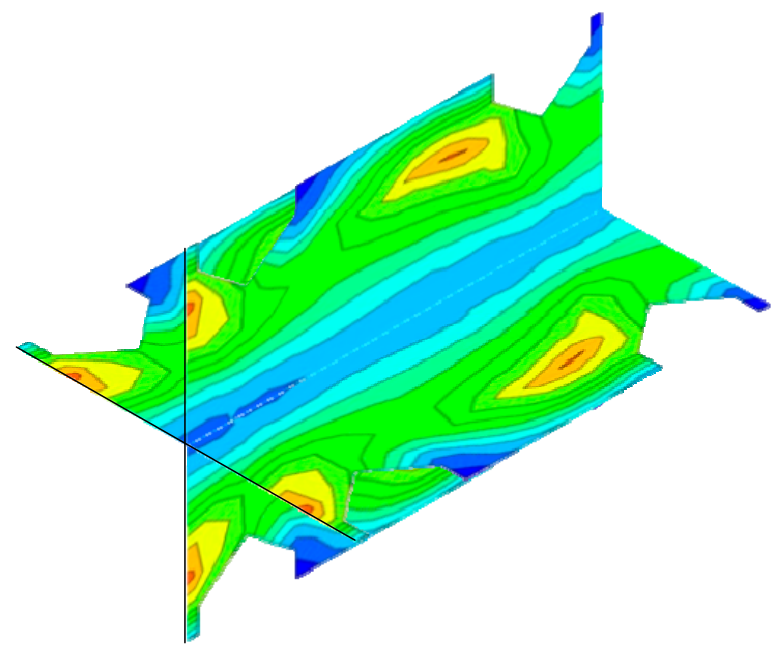

(a) $\mathrm{R}=15 \mathrm{~mm}$

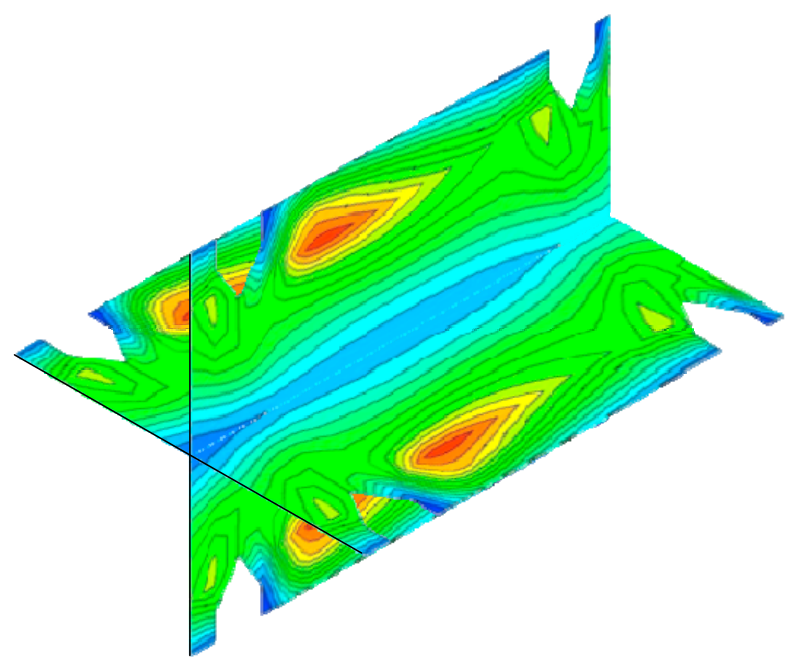

(c) $\mathrm{R}=11 \mathrm{~mm}$

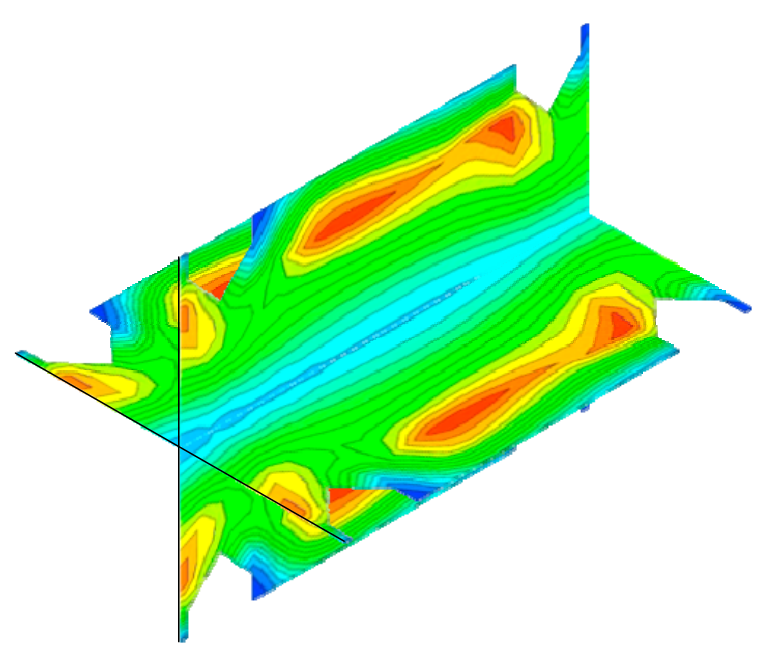

(b) $\mathrm{R}=13 \mathrm{~mm}$

\section{Kinetic energy contour $\quad 1$}

Color map

Figure 14. Kinetic energy contours for various configurations of Case B with different $R$ parameters at $B 2=24 \mathrm{~mm}$, $\operatorname{Re}=15,000$, and $\varphi=0.5 \%$.

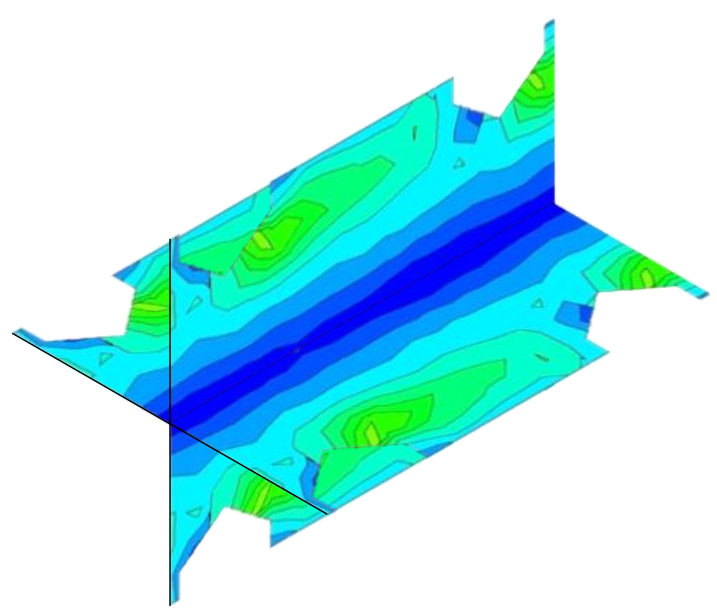

(a) $\mathrm{R}=15 \mathrm{~mm}$

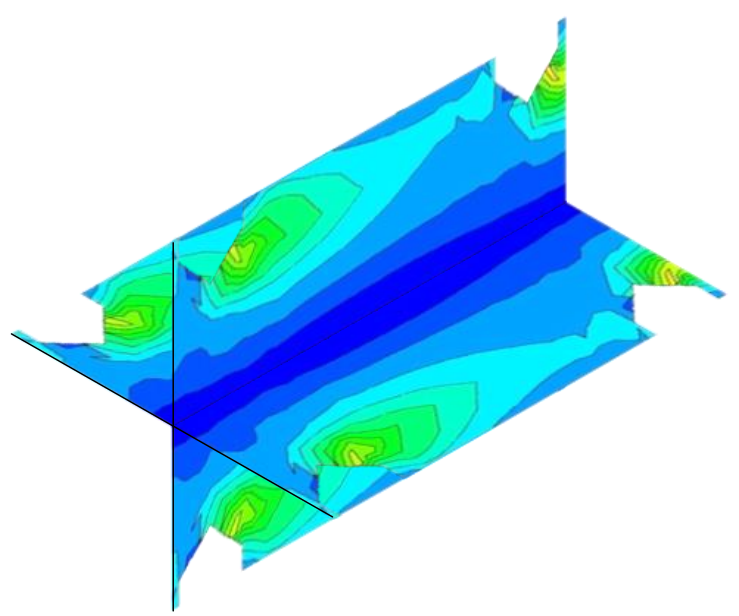

(b) $\mathrm{R}=13 \mathrm{~mm}$

Figure 15. Cont. 


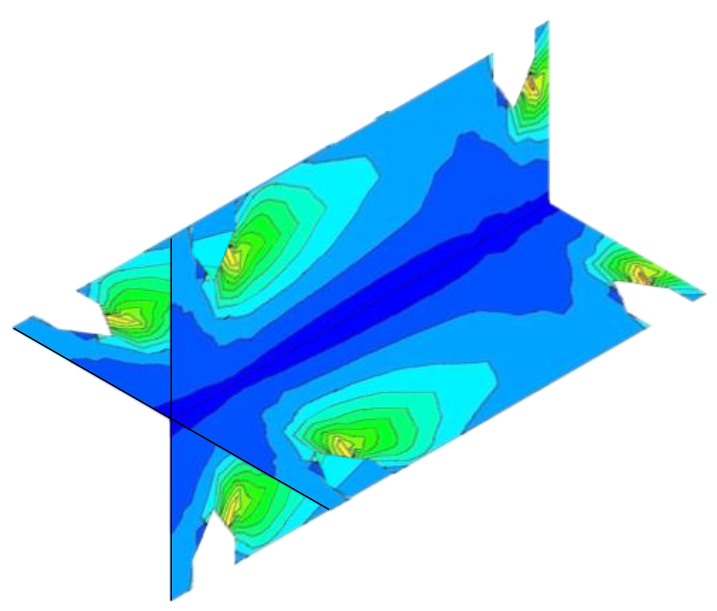

(c) $\mathrm{R}=11 \mathrm{~mm}$

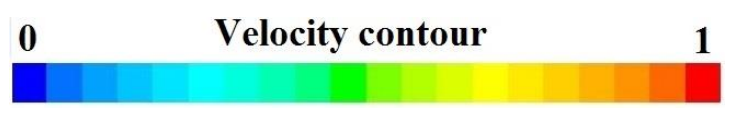

Color map

Figure 15. Velocity magnitude contours for various configurations of Case B with different $R$ parameters at $B 2=24 \mathrm{~mm}$, $\operatorname{Re}=15,000$, and $\varphi=0.5 \%$.

Figure 16 shows streamlines for various configurations of Case $B$ with different $B 2$ parameters at $R=15 \mathrm{~mm}, \operatorname{Re}=15,000$, and $\varphi=0.5 \%$. As can be seen, by changing parameter $B 2$, the streamlines are affected and change. As parameter $B 2$ becomes longer, the formation of vortices and local turbulence in the pipe increases and the flow mixing rate increases. This, on the one hand, increases the heat transfer coefficient, and on the other hand, leads to a greater pressure drop penalty. This can clearly be seen through the reduction in the dark blue color in this section of the tube. Figure 17 illustrates temperature contours for various configurations of Case $B$ with different $B 2$ parameters at $R=15 \mathrm{~mm}, \operatorname{Re}=15,000$, and $\varphi=0.5 \%$. As can be seen, by changing parameter $B 2$, the temperature contours are affected and change. As parameter $B 2$ becomes longer, a reduction in the dark blue color in this section of the tube can be seen. Figure 18 presents kinetic energy contours for various configurations of Case $B$ with different $B 2$ parameters at $R=15 \mathrm{~mm}, \operatorname{Re}=15,000$, and $\varphi=0.5 \%$. A reduction in the light green and blue colors alongside a reduction in parameter $R$ is observed in these figures. The presence of sharp edges in this geometry causes the separation and reversal of the flow, which decreases parameter $R$ and increases parameter $B 2$. The main reason for the formation of the vortex is exactly these sharp edges. Figure 19 demonstrates velocity magnitude contours for various configurations of Case $B$ with different $B 2$ parameters at $R=15 \mathrm{~mm}, \operatorname{Re}=15,000$, and $\varphi=0.5 \%$. This can clearly be seen by the reduction in the dark blue color in this section of the tube alongside a reduction in parameter $R$. However, in order to reduce the volume of the article, contours related to different Reynolds numbers have been omitted. As can be seen, increasing the Reynolds number intensifies the turbulence, increases the flow mixing rate, and increases the vortices. This leads to an increase in heat transfer coefficient as well as an increase in the pressure drop penalty. 


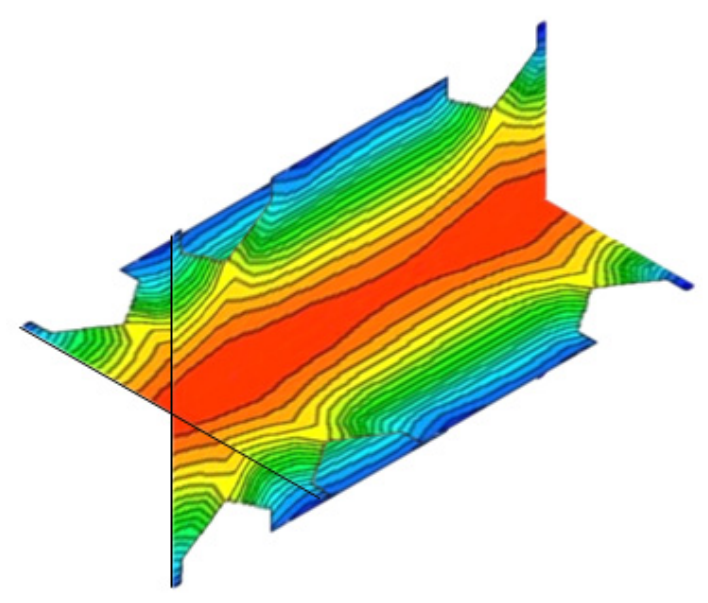

(a) $\mathrm{B}_{2}=26 \mathrm{~mm}$

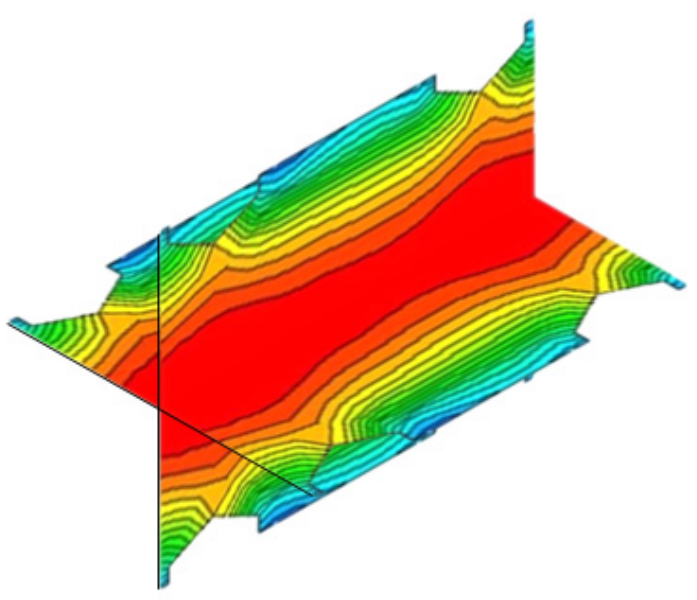

(c) $\mathrm{B}_{2}=22 \mathrm{~mm}$

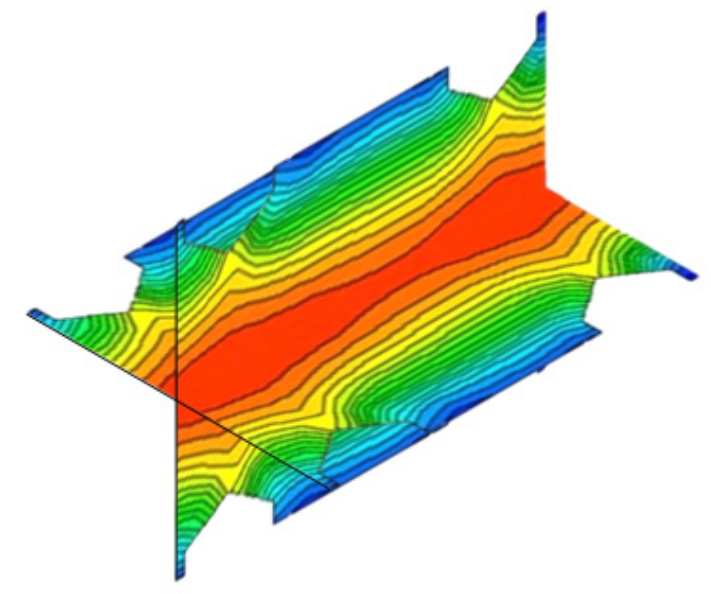

(b) $\mathrm{B}_{2}=24 \mathrm{~mm}$

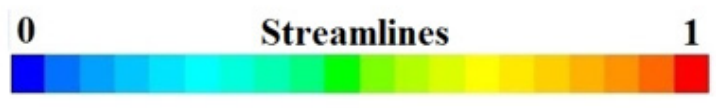

Figure 16. Streamlines for various configurations of Case B with different $B 2$ parameters at $R=15 \mathrm{~mm}, \operatorname{Re}=15,000$, and $\varphi=0.5 \%$.

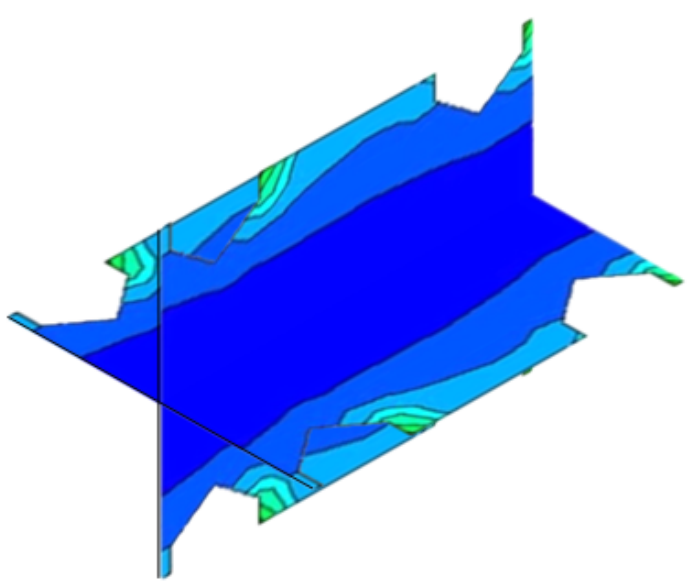

(a) $\mathrm{B}_{2}=26 \mathrm{~mm}$

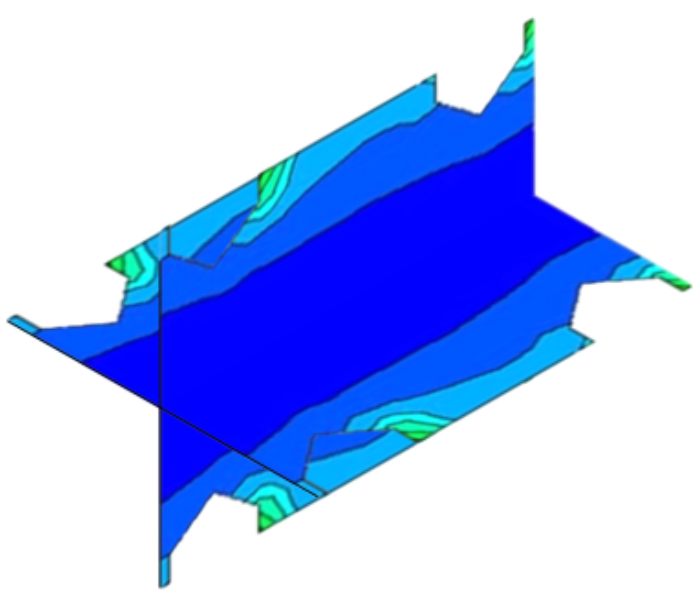

(b) $\mathrm{B}_{2}=24 \mathrm{~mm}$

Figure 17. Cont. 


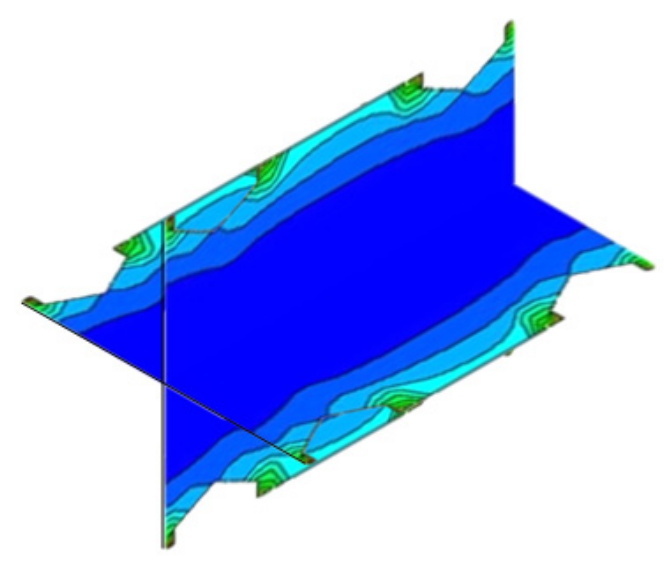

(c) $\mathrm{B}_{2}=22 \mathrm{~mm}$

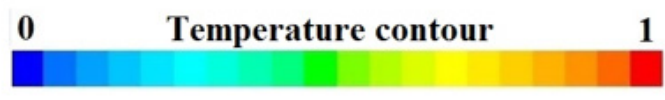

Color map

Figure 17. Temperature contours for various configurations of Case $B$ with different $B 2$ parameters at $R=15 \mathrm{~mm}, \operatorname{Re}=15,000$, and $\varphi=0.5 \%$.

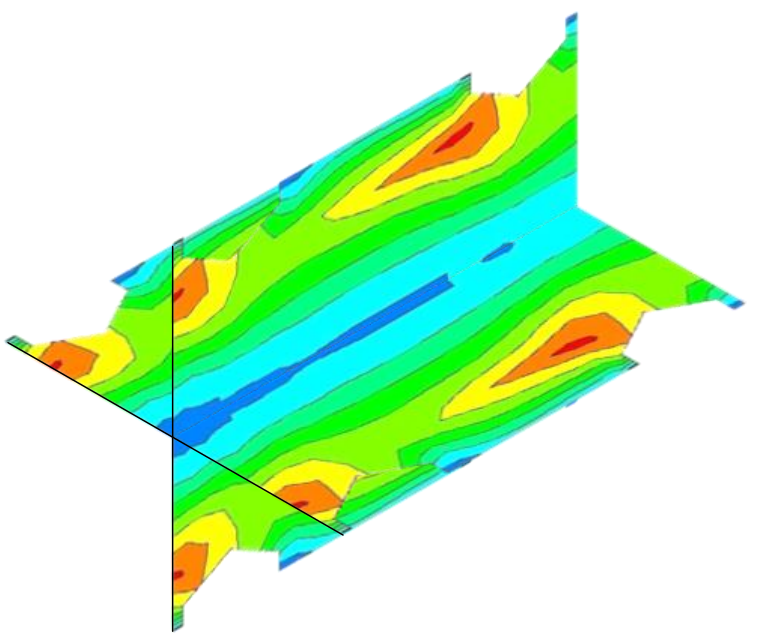

(a) $\mathrm{B}_{2}=26 \mathrm{~mm}$

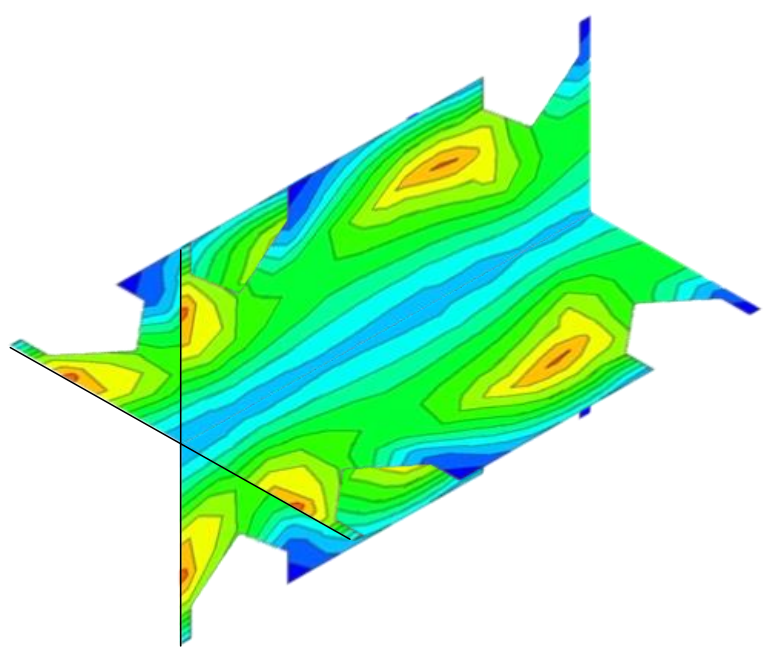

(c) $\mathrm{B}_{2}=22 \mathrm{~mm}$

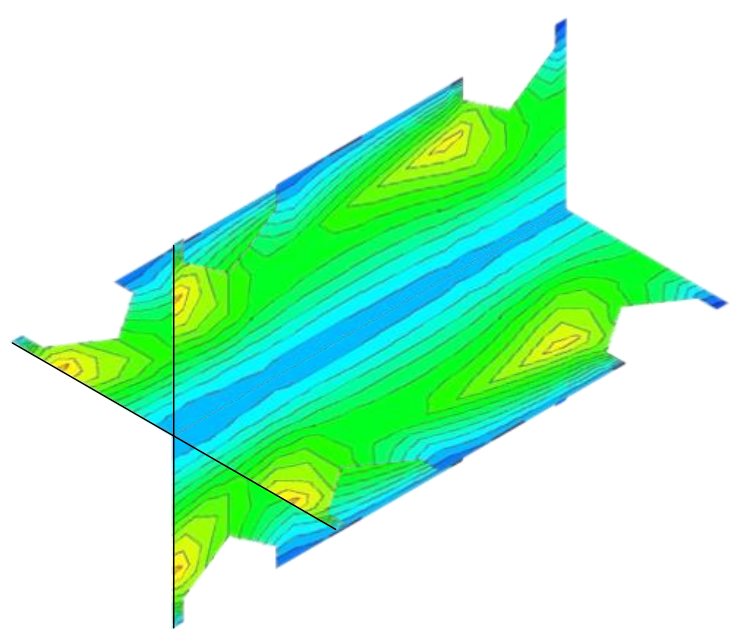

(b) $\mathrm{B}_{2}=24 \mathrm{~mm}$

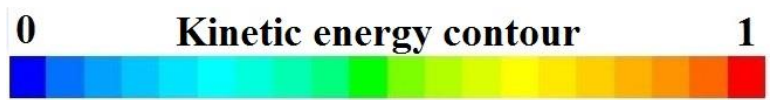

Figure 18. Kinetic energy contours for various configurations of Case B with different $B 2$ parameters at $R=15 \mathrm{~mm}$, $\operatorname{Re}=15,000$, and $\varphi=0.5 \%$. 


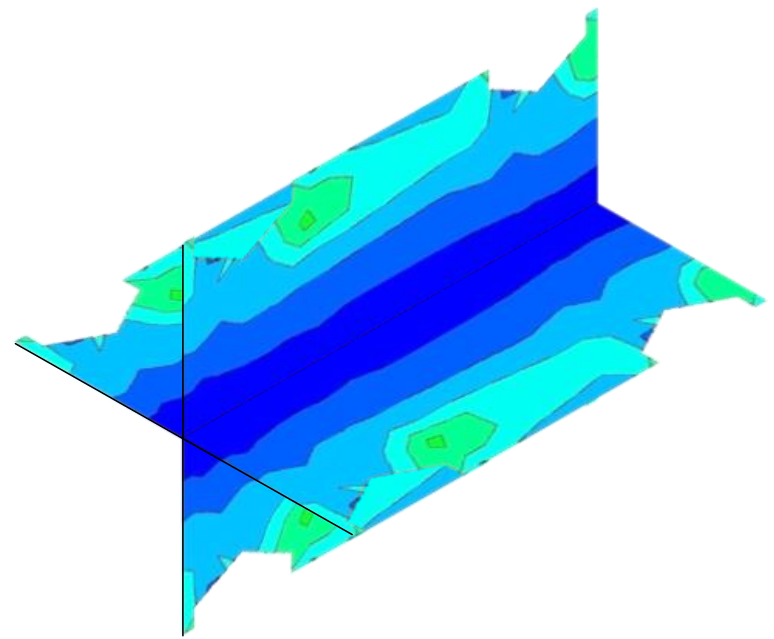

(a) $\mathrm{B}_{2}=26 \mathrm{~mm}$

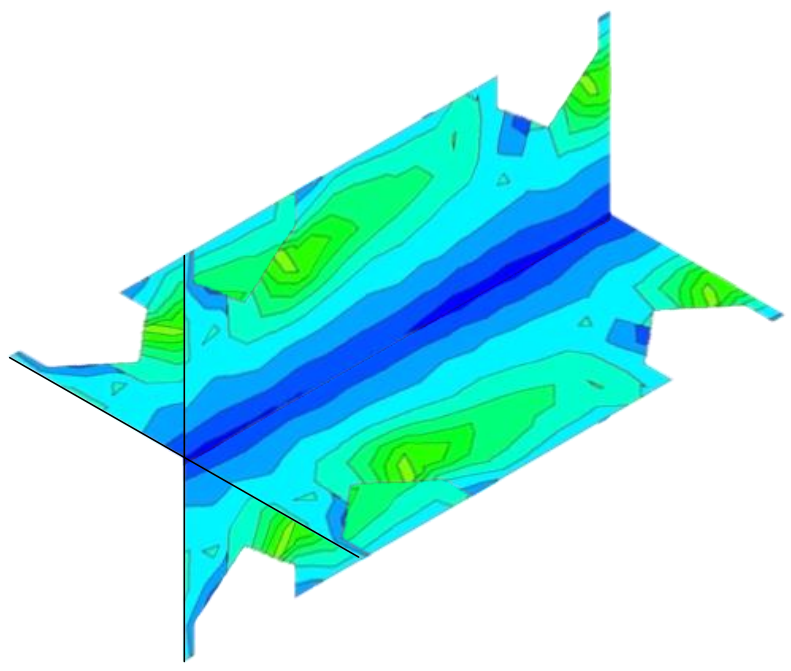

(c) $\mathrm{B}_{2}=22 \mathrm{~mm}$

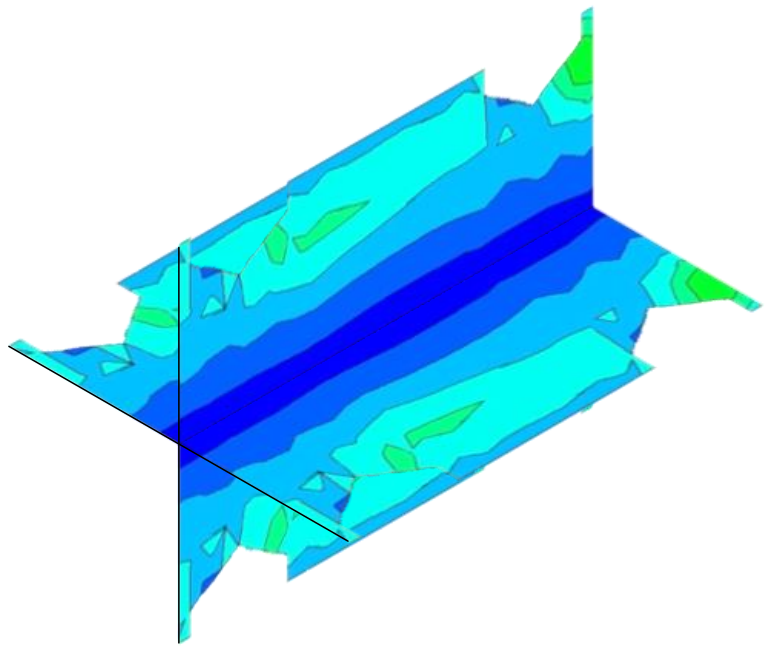

(b) $\mathrm{B}_{2}=24 \mathrm{~mm}$

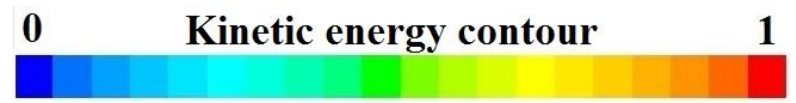

Color map

Figure 19. Velocity magnitude contours for various configurations of Case B with different $B 2$ parameters at $R=15 \mathrm{~mm}$, $\operatorname{Re}=15,000$, and $\varphi=0.5 \%$.

\subsection{Case $C$}

In Case $C$, two parameters are variable; $R$ and $C 2$. First, the variations in the $R$ parameter are examined and then parameter $C 2$ is analyzed. Thus, streamlines and temperature contours are used. Figure 20 shows streamlines for various configurations of Case $C$ with different $R$ parameters at $C 2=24 \mathrm{~mm}, \operatorname{Re}=15,000$, and $\varphi=0.5 \%$. As can be seen, by changing parameter $R$, the streamlines are affected and change. As parameter $R$ becomes smaller, the formation of vortices and local turbulence in the pipe increases and the flow mixing rate increases. This, on the one hand, increases the heat transfer coefficient, and on the other hand, leads to a greater pressure drop penalty. This can clearly be seen through the reduction in the dark blue color in this section of the tube. Figure 21 illustrates temperature contours for various configurations of Case $C$ with different $R$ parameters at $C 2=24 \mathrm{~mm}, \operatorname{Re}=15,000$, and $\varphi=0.5 \%$. As can be seen, by changing parameter $R$, the temperature contours are affected and change. As parameter $R$ becomes smaller, a reduction in the dark blue color in this section of the tube can be seen. The presence of sharp edges in this geometry causes the separation and reversal of the flow, which decreases parameter $R$ and increases parameter $C 2$. The main reason for the formation of the vortex is exactly these sharp edges. However, to reduce the volume of the article, contours related 
to different Reynolds numbers have been omitted. As can be seen, increasing the Reynolds number intensifies the turbulence, increases the flow mixing rate, and increases the vortices. This leads to an increase in heat transfer coefficient as well as an increase in the pressure drop penalty.

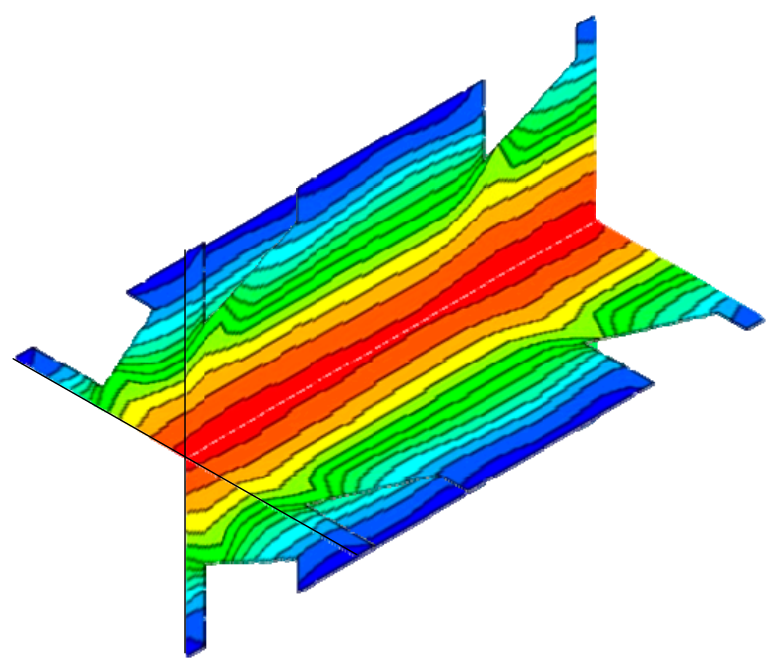

(a) $\mathrm{R}=15 \mathrm{~mm}$

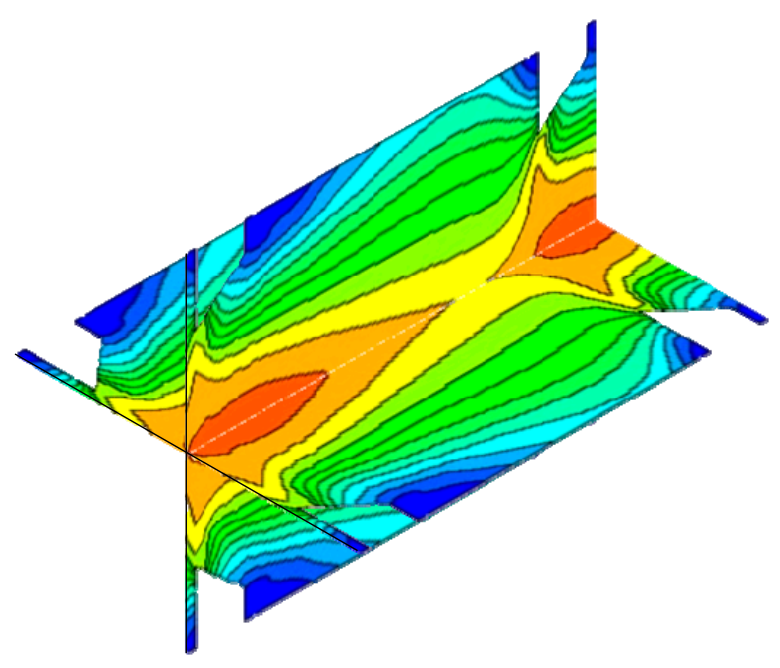

(c) $\mathrm{R}=11 \mathrm{~mm}$

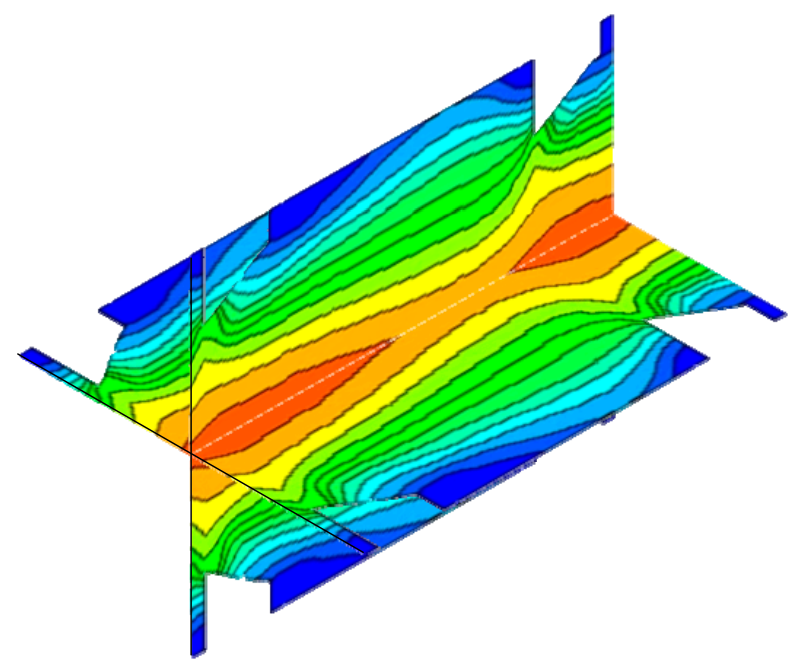

(b) $\mathrm{R}=13 \mathrm{~mm}$

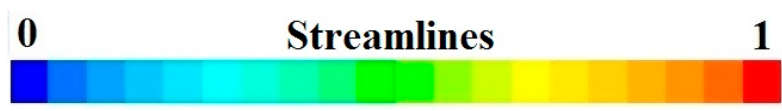

Figure 20. Streamlines for various configurations of Case $C$ with different $R$ parameters at $C 2=24 \mathrm{~mm}, \operatorname{Re}=15,000$, and $\varphi=0.5 \%$.

Figure 22 shows streamlines for various configurations of Case $C$ with different $C 2$ parameters at $R=15 \mathrm{~mm}, \operatorname{Re}=15,000$, and $\varphi=0.5 \%$. As can be seen, by changing parameter $C 2$, the streamlines are affected and change. As parameter $C 2$ becomes longer, the formation of vortices and local turbulence in the pipe increases and the flow mixing rate increases. This, on the one hand, increases the heat transfer coefficient, and on the other hand, leads to a greater pressure drop penalty. This can clearly be seen by the reduction in the dark blue color in this section of the tube.

Figure 23 illustrates temperature contours for various configurations of Case $C$ with different $C 2$ parameters at $R=15 \mathrm{~mm}, \operatorname{Re}=15,000$, and $\varphi=0.5 \%$. As can be seen, by changing parameter $C 2$, the temperature contours are affected and change. As parameter $\mathrm{C} 2$ becomes longer, a reduction in the dark blue color in this section of the tube can be seen. 


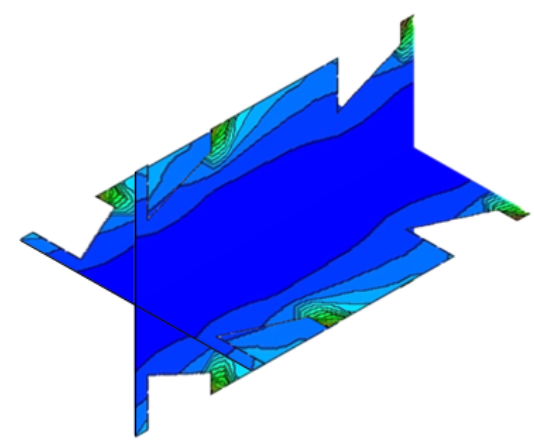

(a) $\mathrm{R}=15 \mathrm{~mm}$

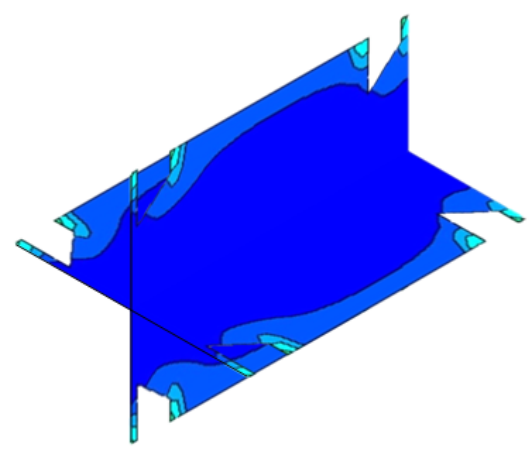

(c) $\mathrm{R}=11 \mathrm{~mm}$

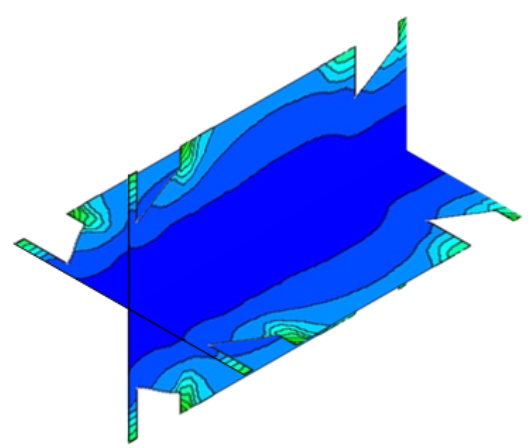

(b) $\mathrm{R}=13 \mathrm{~mm}$

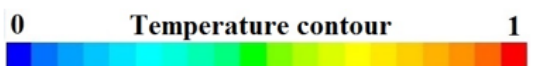

Figure 21. Temperature contours for various configurations of Case $C$ with different $R$ parameters at $C 2=24 \mathrm{~mm}, \operatorname{Re}=15,000$, and $\varphi=0.5 \%$.

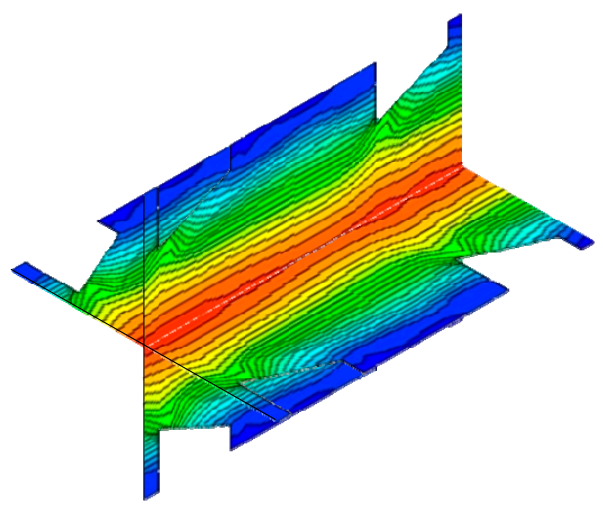

(a) $C_{2}=26 \mathrm{~mm}$

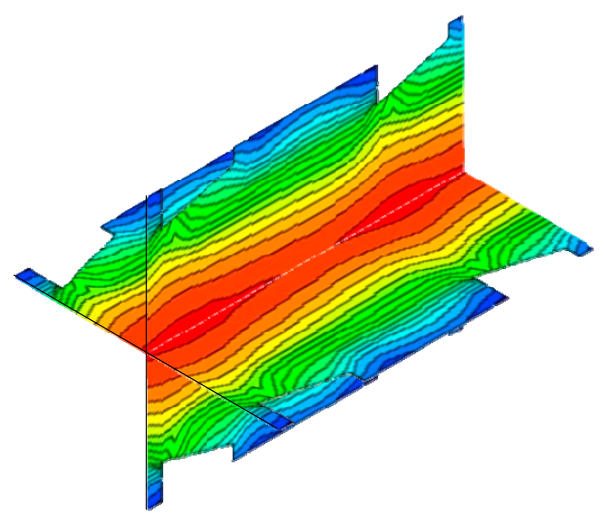

(c) $C_{2}=22 \mathrm{~mm}$

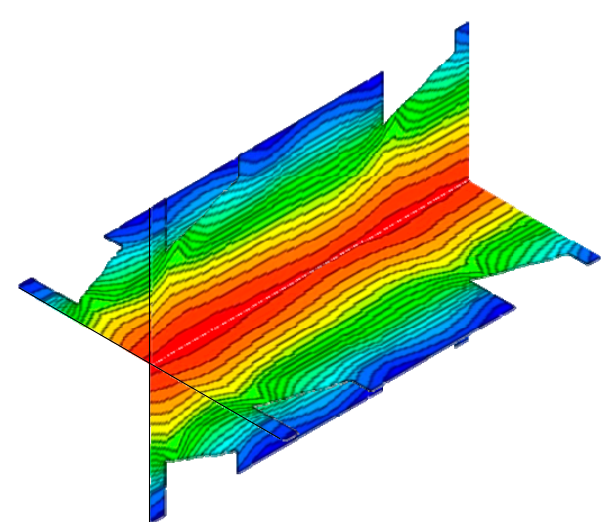

(b) $\mathrm{C}_{2}=24 \mathrm{~mm}$

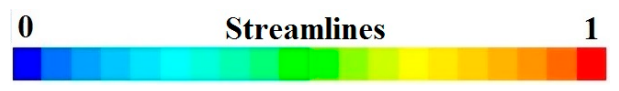

Color map

Figure 22. Streamlines for various configurations of Case $C$ with different $C 2$ parameters at $R=15 \mathrm{~mm}, \operatorname{Re}=15,000$, and $\varphi=0.5 \%$. 


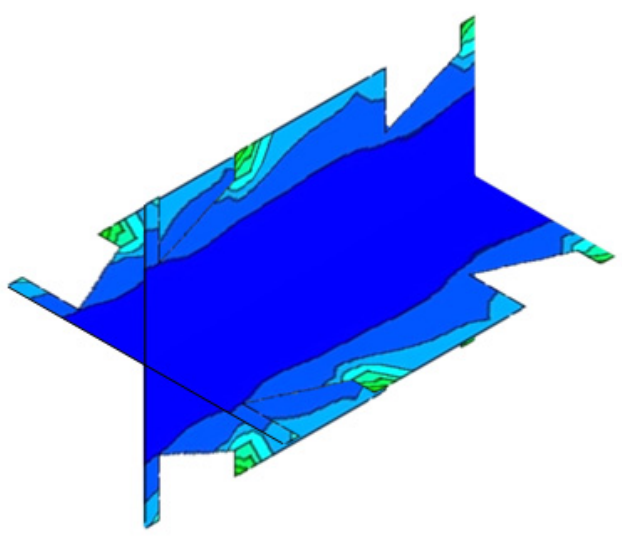

(a) $\mathrm{C}_{2}=26 \mathrm{~mm}$

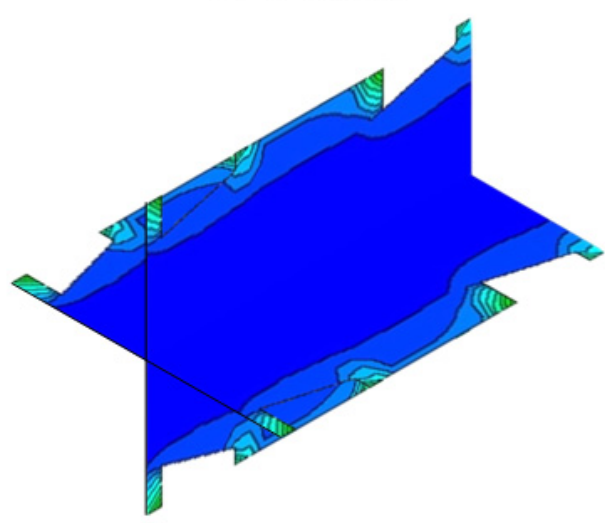

(c) $\mathrm{C}_{2}=22 \mathrm{~mm}$

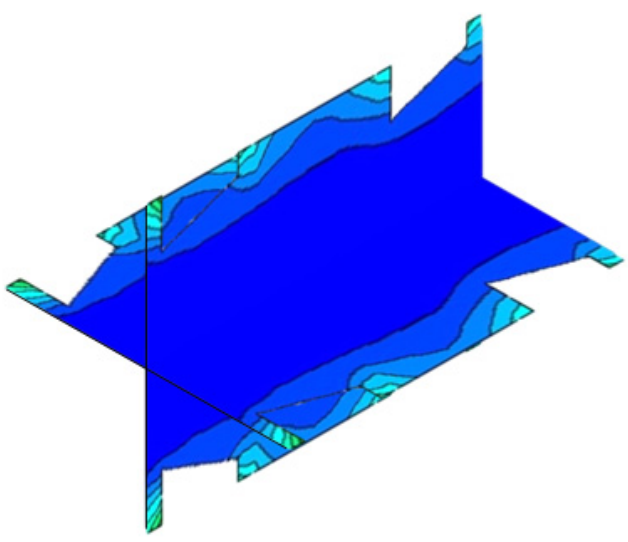

(b) $\mathrm{C}_{2}=24 \mathrm{~mm}$

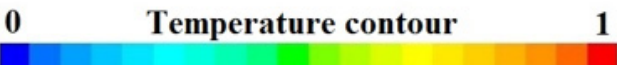

Color map

Figure 23. Temperature contours for various configurations of Case $C$ with different $C 2$ parameters at $R=15 \mathrm{~mm}, \operatorname{Re}=15,000$, and $\varphi=0.5 \%$.

However, in order to reduce the volume of the article, contours related to different Reynolds numbers have been omitted. As can be seen, increasing the Reynolds number intensifies the turbulence, increases the flow mixing rate, and increases the vortices. This leads to an increase in heat transfer coefficient as well as an increase in the pressure drop penalty.

\subsection{Case $D$}

Figure 24 shows streamlines, temperature, kinetic energy, and velocity magnitude contours for Case $D$ with $R=15 \mathrm{~mm}, D 1=12 \mathrm{~mm}$, and $D 2=24 \mathrm{~mm}$ parameters at $\operatorname{Re}=15,000$ and $\varphi=0.5 \%$. Additionally, Figure 25 demonstrates streamlines, temperature, kinetic energy, and velocity magnitude contours for Case $D$ with $R=15 \mathrm{~mm}, D 1=12 \mathrm{~mm}$, and D2 $=26 \mathrm{~mm}$ parameters at $\operatorname{Re}=15,000$ and $\varphi=0.5 \%$. As can be seen, by changing parameter $D 2$, the streamlines, temperature contours, kinetic energy contours, and velocity magnitude contours are affected and change. As parameter D2 becomes longer, the formation of vortices and local turbulence in the pipe increases and the flow mixing rate increases. This, on the one hand, increases the heat transfer coefficient, and on the other hand, leads to a greater pressure drop penalty. This can clearly be seen by the reduction in the dark blue color in this section of the tube. However, in order to reduce the volume of the article, contours related to different Reynolds numbers have been omitted. As can be seen, increasing the Reynolds number intensifies the turbulence, increases the flow mixing rate, and increases the vortices. This leads to an increase in heat transfer coefficient as well as an increase in the pressure drop penalty. 

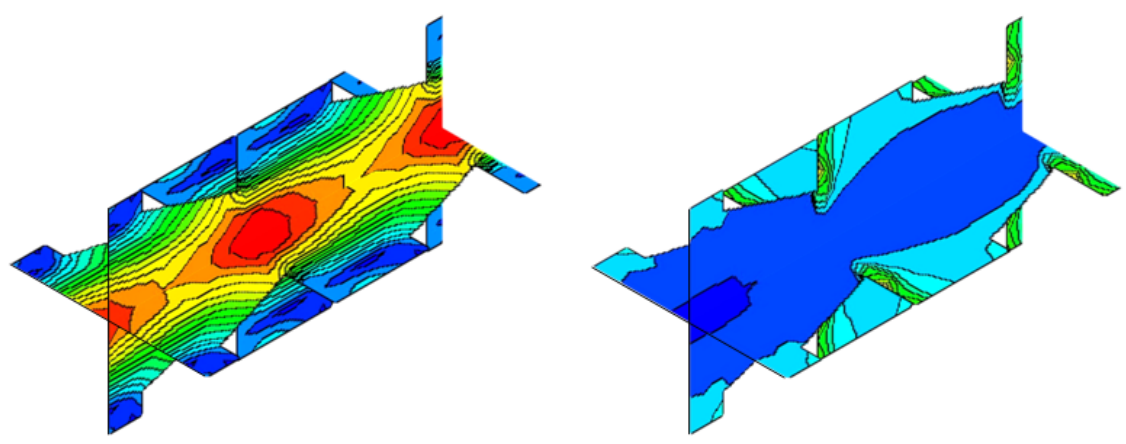

0

\section{Streamlines}
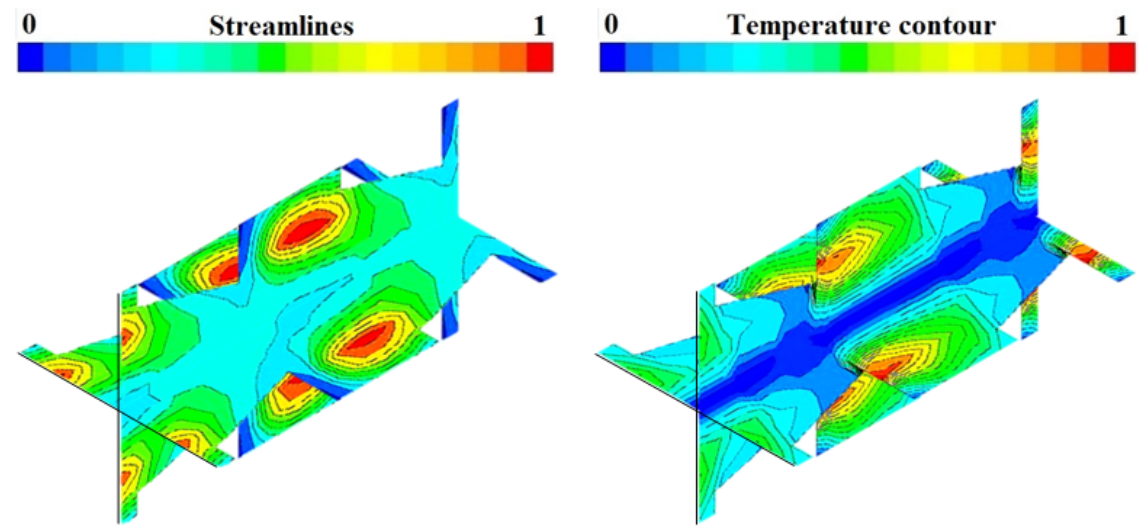

o
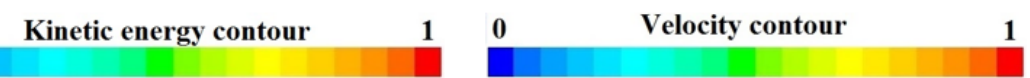

Figure 24. Streamlines, temperature, kinetic energy and velocity magnitude contours for Case $\mathrm{D}$ with $R=15 \mathrm{~mm}$, $D 1=12 \mathrm{~mm}$, and $D 2=24 \mathrm{~mm}$ parameters at $\operatorname{Re}=15,000$, and $\varphi=0.5 \%$.
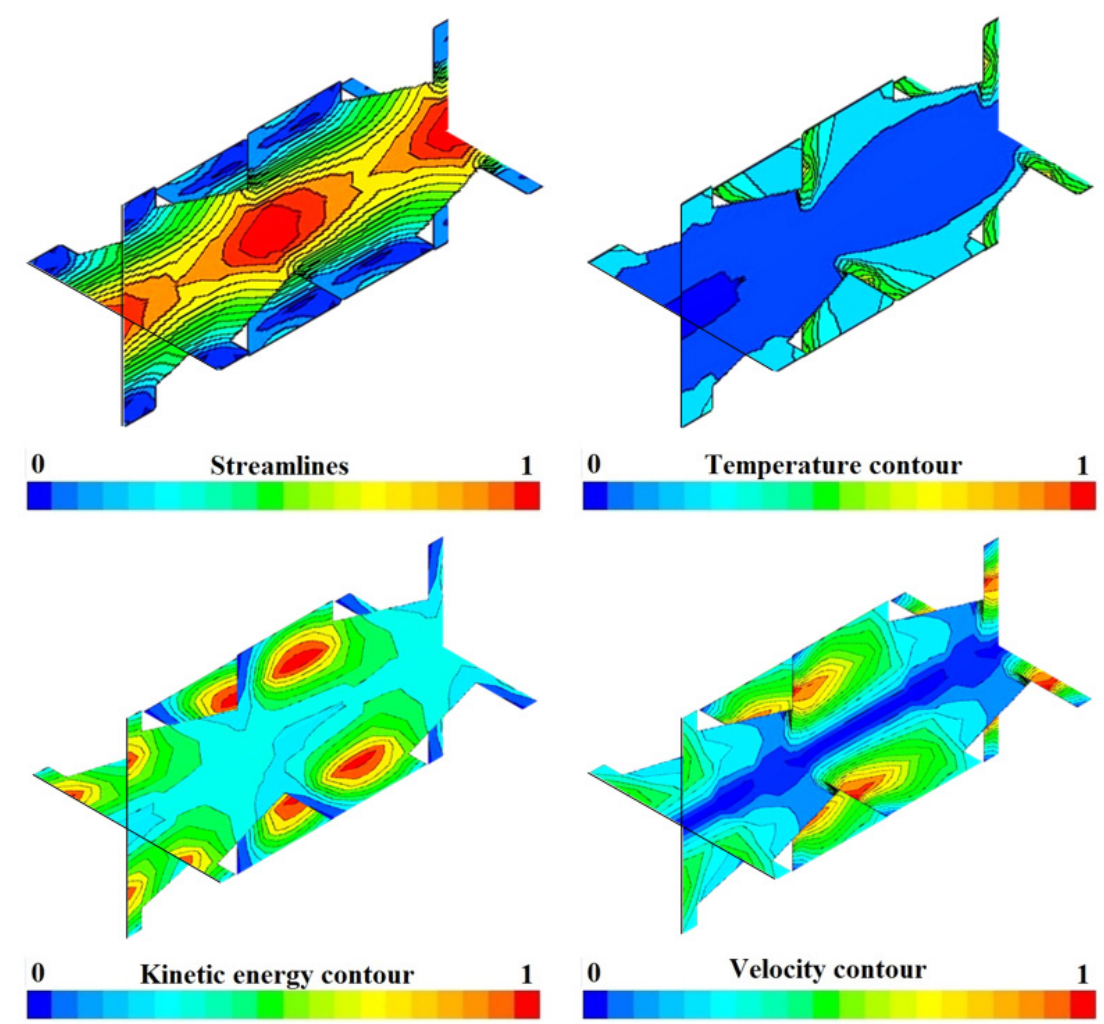

Figure 25. Streamlines, temperature, kinetic energy and velocity magnitude contours for Case $\mathrm{D}$ with $R=15 \mathrm{~mm}$, $D 1=12 \mathrm{~mm}$, and $D 2=26 \mathrm{~mm}$ parameters at $\operatorname{Re}=15,000$, and $\varphi=0.5 \%$. 


\subsection{Case $E$}

In Case $\mathrm{E}$ two parameters are variable; $R$ and E2. First, the variations in the $R$ parameter are examined and then parameter $E 2$ is analyzed. In that manner, temperature contours and streamlines are used. Figure 26 shows streamlines and temperature contours for various configurations of Case $E$ with different $R$ parameters at $E 2=24 \mathrm{~mm}, R e=15,000$, and $\varphi=0.5 \%$. As can be seen, when we change parameter $R$, the streamlines are affected and change. As parameter $R$ becomes smaller, the formation of vortices and local turbulence in the pipe increases and the flow mixing rate increases. This, on the one hand, increases the heat transfer coefficient, and on the other hand, leads to a greater pressure drop penalty. This can clearly be seen through the reduction in the dark blue color in this section of the tube. Figure 27 shows streamlines and temperature contours for various configurations of Case $E$ with different $R$ parameters at $E 2=24 \mathrm{~mm}, \operatorname{Re}=19,000$, and $\varphi=0.5 \%$. As can be seen, by changing parameter $R$, the streamlines are affected and change. As parameter $R$ becomes smaller, the formation of vortices and local turbulence in the pipe increases and the flow mixing rate increases. This, on the one hand, increases the heat transfer coefficient, and on the other hand, leads to a greater pressure drop penalty. This can clearly be seen by the reduction in the dark blue color in this section of the tube. It is seen that increasing the Reynolds number intensifies the turbulence, increases the flow mixing rate, and increases the vortices. This leads to an increase in heat transfer coefficient as well as an increase in the pressure drop penalty. There is always an optimum Reynolds number, where the maximum PEC value is occurred.

(a) $\mathrm{R}=15 \mathrm{~mm}$

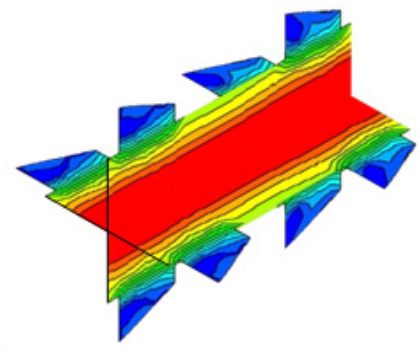

(c) $\mathrm{R}=13 \mathrm{~mm}$

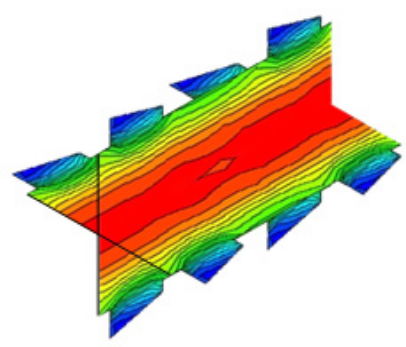

(e) $\mathrm{R}=11 \mathrm{~mm}$

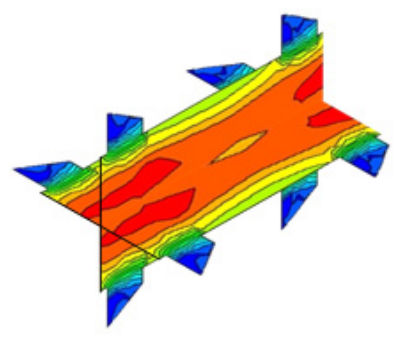

0 (b) $\mathrm{R}=15 \mathrm{~mm}$

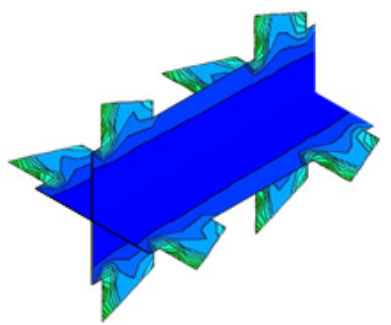

(d) $\mathrm{R}=13 \mathrm{~mm}$

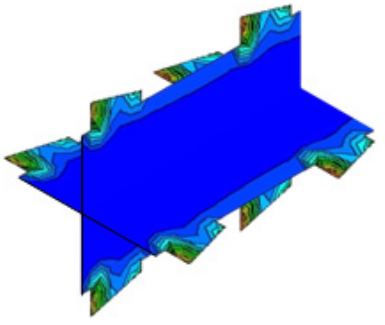

(f) $\mathrm{R}=11 \mathrm{~mm}$

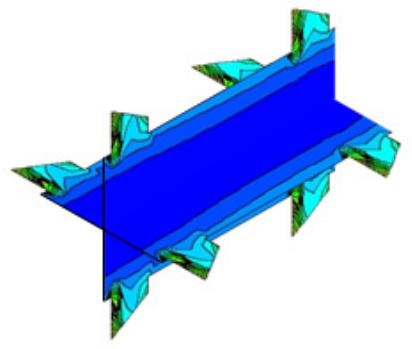

O
Temperature contour

Figure 26. Streamlines and temperature contours for various configurations of Case $\mathrm{E}$ with different $R$ parameters at $E 2=24 \mathrm{~mm}, \operatorname{Re}=15,000$, and $\varphi=0.5 \%$. 
(a) $\mathrm{R}=15 \mathrm{~mm}$

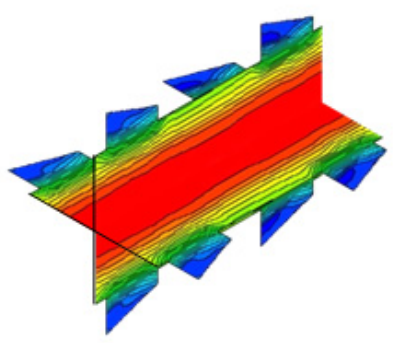

(c) $\mathrm{R}=13 \mathrm{~mm}$

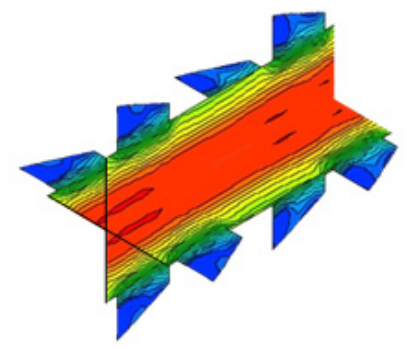

(e) $\mathrm{R}=11 \mathrm{~mm}$

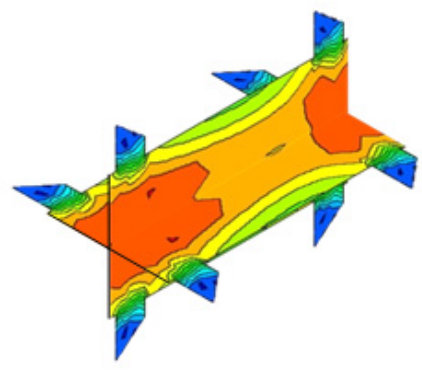

0

Streamlines (b) $\mathrm{R}=15 \mathrm{~mm}$

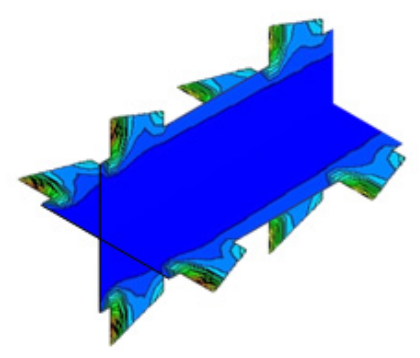

(d) $\mathrm{R}=13 \mathrm{~mm}$

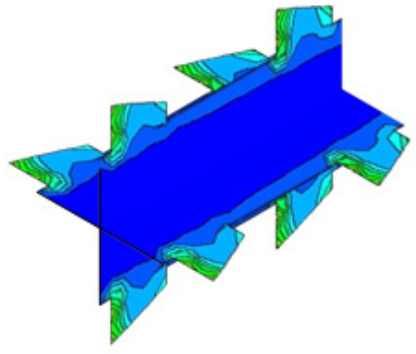

(f) $\mathrm{R}=11 \mathrm{~mm}$

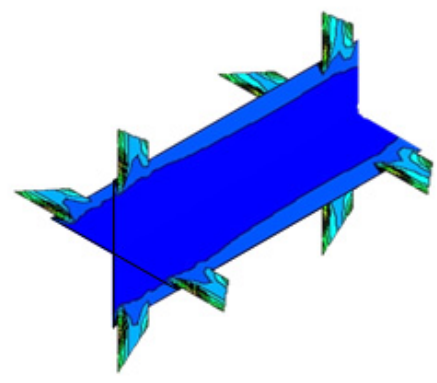

$\mathbf{0}$
1

Figure 27. Streamlines and temperature contours for various configurations of Case $\mathrm{E}$ with different $R$ parameters at $E 2=24 \mathrm{~mm}, \operatorname{Re}=19,000$, and $\varphi=0.5 \%$.

\subsection{Case F}

In Case F, just one parameter is variable; F. Velocity and kinetic energy contours, temperature, and streamlines were the options used here. Figure 28 shows streamlines for various configurations of Case $\mathrm{E}$ with different $F$ parameters at $\operatorname{Re}=15,000$ and $\varphi=0.5 \%$. As can be seen, by changing parameter $F$, the streamlines are affected and change. As parameter $F$ becomes smaller, the formation of vortices and local turbulence in the pipe increases and the flow mixing rate increases. This, on the one hand, increases the heat transfer coefficient, and on the other hand, leads to a greater pressure drop penalty. This can clearly be seen by the reduction in the dark blue color in this section of the tube. Figure 29 illustrates temperature contours for various configurations of Case $\mathrm{F}$ with different $F$ parameters at $\operatorname{Re}=15,000$ and $\varphi=0.5 \%$. As can be seen, by changing parameter $F$, the temperature contours are affected and change. As parameter $F$ becomes smaller, a reduction in the dark blue color in this section of the tube can be seen. The presence of sharp edges in this geometry causes the separation and reversal of the flow, which decreases parameter $F$. The main reason for the formation of the vortex is exactly these sharp edges. Figure 30 presents kinetic energy contours for various configurations of Case $\mathrm{F}$ with different $F$ parameters at $\operatorname{Re}=15,000$ and $\varphi=0.5 \%$. A reduction in light green and blue colors with a reduction in parameter $R$ is observed in these figures. Figure 31 demonstrates velocity magnitude contours for various configurations of Case $\mathrm{F}$ with different $F$ parameters at $\operatorname{Re}=15,000$ and $\varphi=0.5 \%$. This can clearly be seen by the reduction in the dark blue color in this section of the tube alongside a reduction in parameter $F$. However, in order to 
reduce the volume of the article, contours related to different Reynolds numbers have been omitted. As can be seen, increasing the Reynolds number intensifies the turbulence, increases the flow mixing rate, and increases the vortices. This leads to an increase in heat transfer coefficient as well as an increase in the pressure drop penalty.

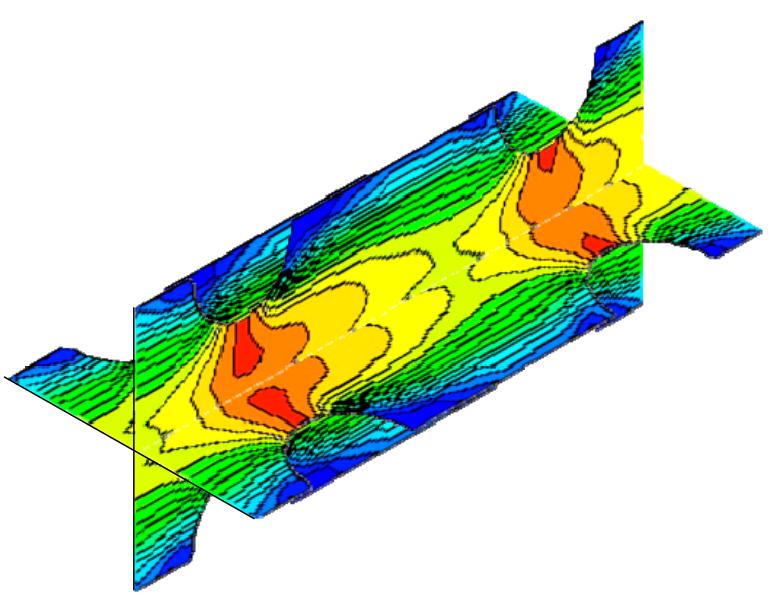

(a) $\mathrm{F}=15 \mathrm{~mm}$

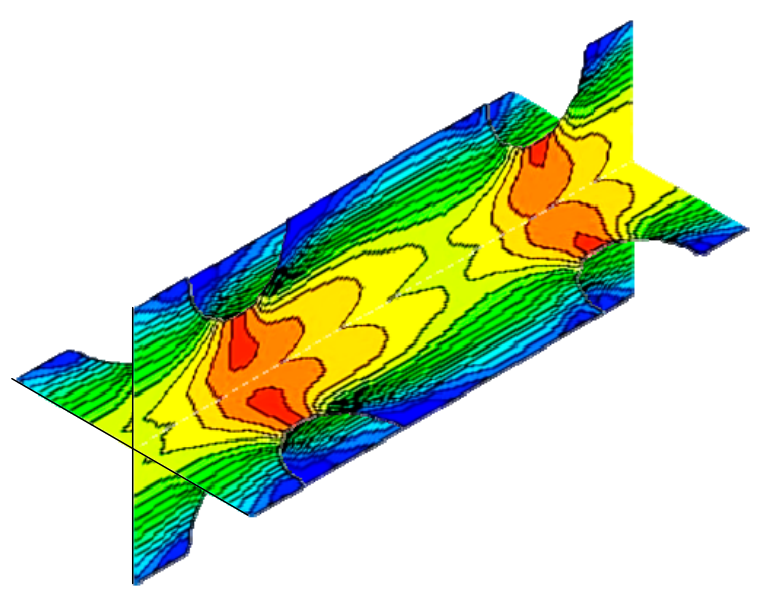

(c) $\mathrm{F}=11 \mathrm{~mm}$

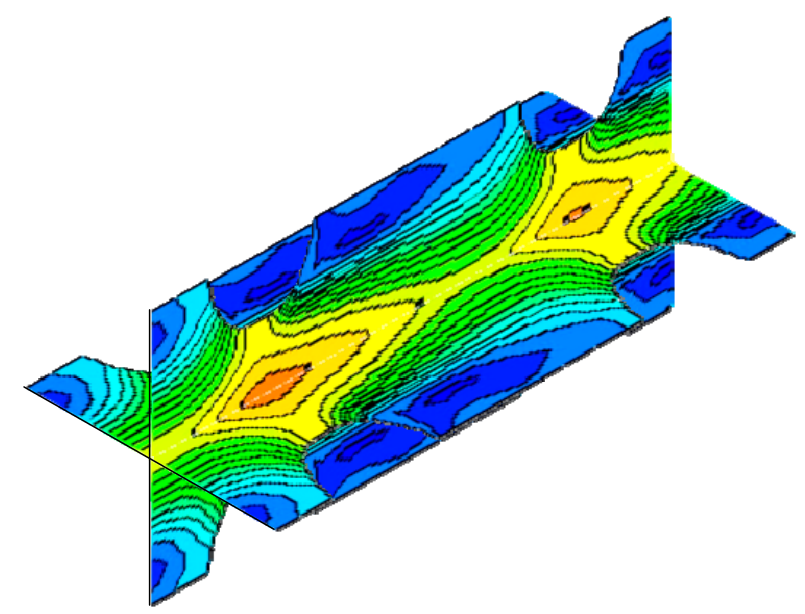

(b) $\mathrm{F}=13 \mathrm{~mm}$

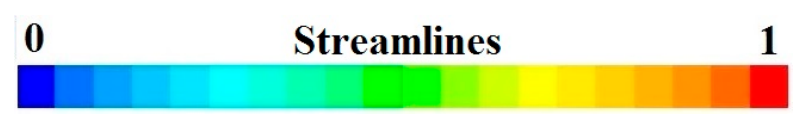

Color map

Figure 28. Streamlines for various configurations of Case $\mathrm{F}$ with different $F$ parameters at $\operatorname{Re}=15,000$, and $\varphi=0.5 \%$. 


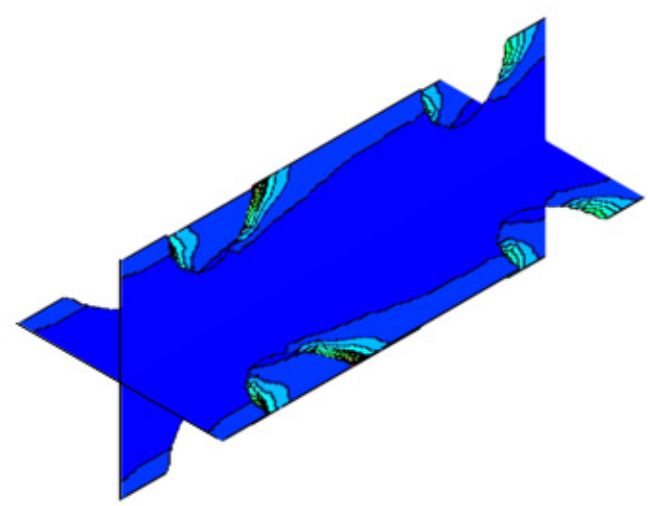

(a) $\mathrm{F}=15 \mathrm{~mm}$

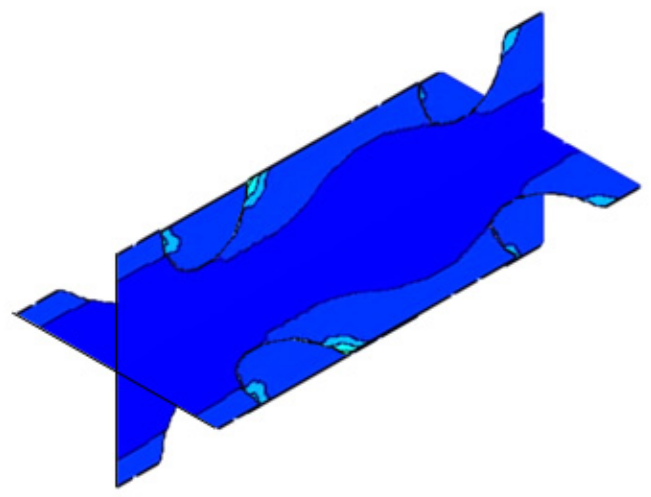

(c) $\mathrm{F}=11 \mathrm{~mm}$

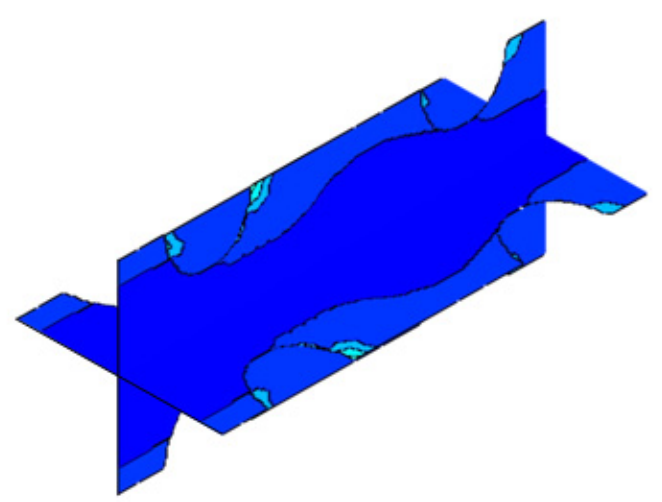

(b) $\mathrm{F}=13 \mathrm{~mm}$

Figure 29. Temperature contours for various configurations of Case $\mathrm{F}$ with different $F$ parameters at $\operatorname{Re}=15,000$, and $\varphi=0.5 \%$.

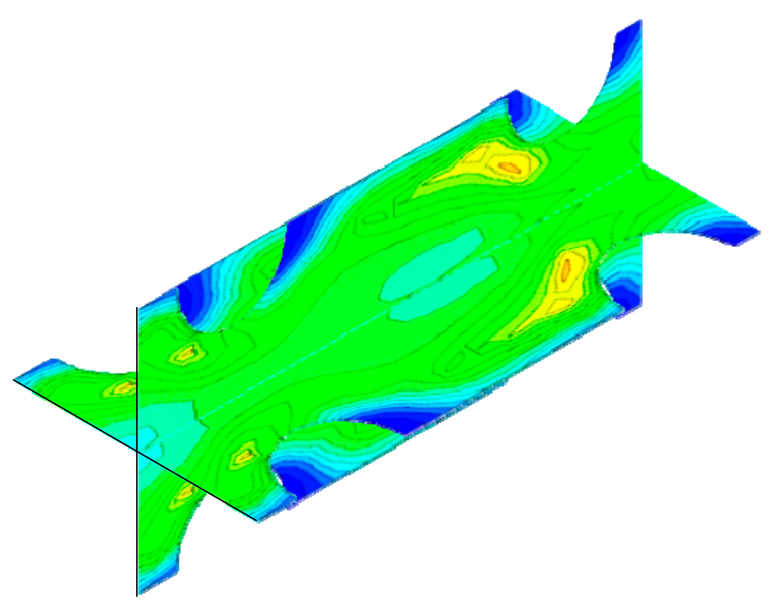

(a) $\mathrm{F}=15 \mathrm{~mm}$

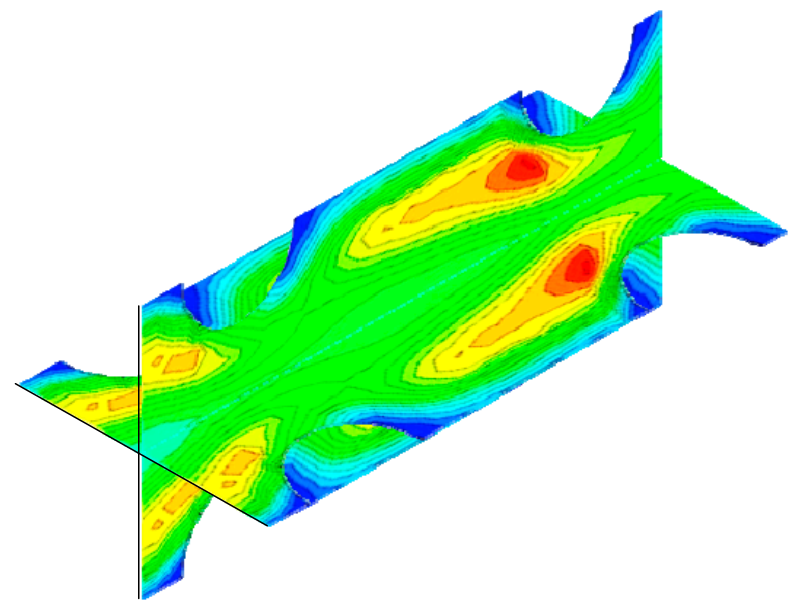

(b) $\mathrm{F}=13 \mathrm{~mm}$

Figure 30. Cont. 


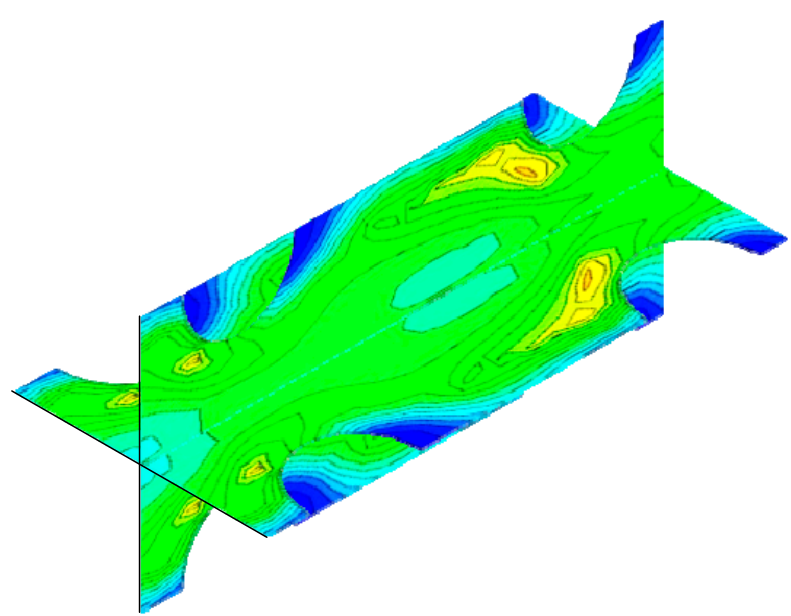

(c) $\mathrm{F}=11 \mathrm{~mm}$

$\mathbf{0}$

Color map

Figure 30. Kinetic energy contours for various configurations of Case $\mathrm{F}$ with different $F$ parameters at $\operatorname{Re}=15,000$, and $\varphi=0.5 \%$.

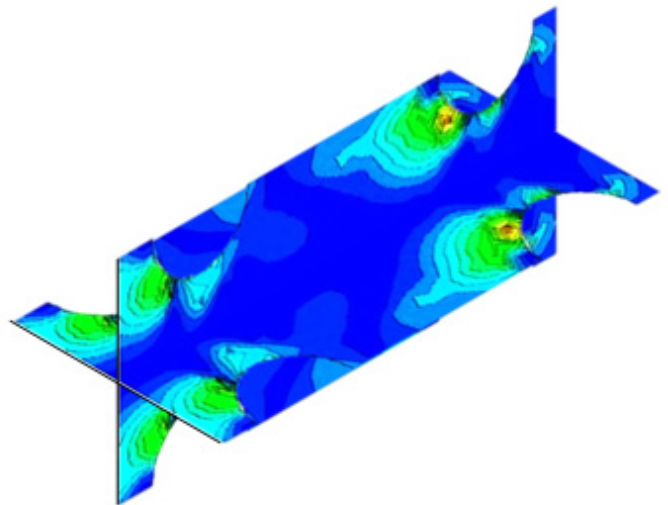

(a) $\mathrm{F}=15 \mathrm{~mm}$

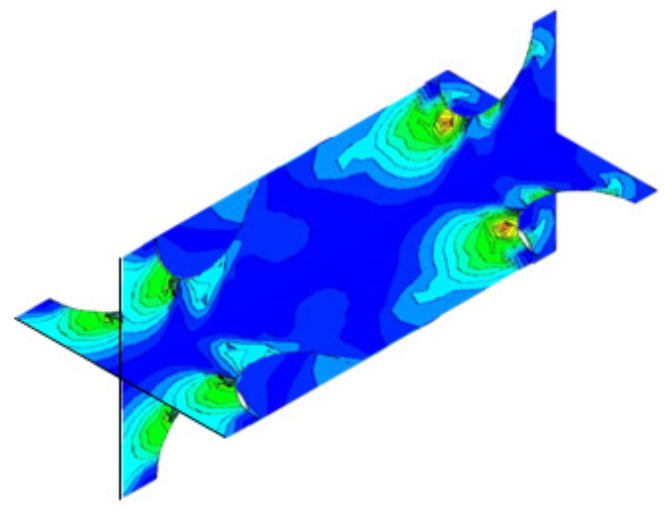

(c) $\mathrm{F}=11 \mathrm{~mm}$

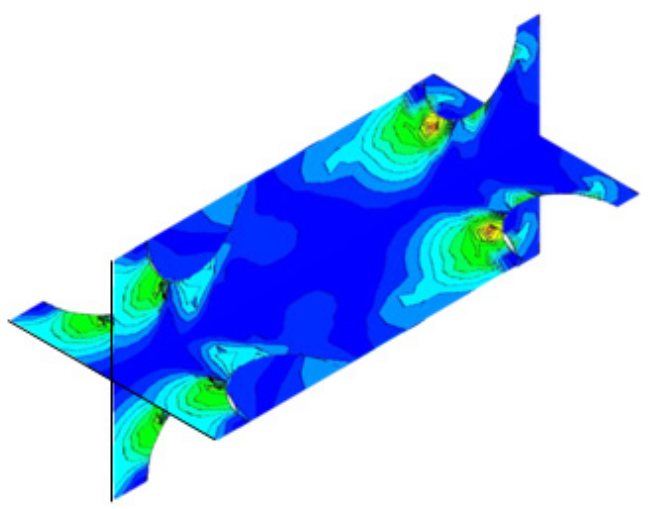

(b) $F=13 \mathrm{~mm}$

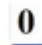

0

Velocity contour

1

Figure 31. Velocity magnitude contours for various configurations of Case $\mathrm{F}$ with different $F$ parameters at $\operatorname{Re}=15,000$, and $\varphi=0.5 \%$. 


\subsection{Comparison}

According to the results and the calculation of the PEC index, the optimum configurations for the different cases are as followss:

Case A: $R=15 \mathrm{~mm}$ and $A 2=24 \mathrm{~mm}$

Case B: $R=15 \mathrm{~mm}$ and $B 2=26 \mathrm{~mm}$

Case $C: R=13 \mathrm{~mm}$ and $B 2=22 \mathrm{~mm}$

Case D: $R=13 \mathrm{~mm}$ and $B 2=24 \mathrm{~mm}$

Case E: $R=15 \mathrm{~mm}$ and $B 2=24 \mathrm{~mm}$

Case F: $F=15 \mathrm{~mm}$

To achieve the optimum case, a comparison of these optimum configurations is made using the PEC index. Figure 32 shows the PEC variation for optimum configurations of different cases at $\operatorname{Re}=11,000$. It can be seen that Case D has the most optimum PEC values and is followed by Cases B, F, C, A, and E, respectively. Additionally, it is seen that an increase in nanoparticle volume fraction leads to higher PEC values. Additionally, Figure 33 illustrates PEC variation versus different Reynolds numbers for optimum configurations of Case D. As can be seen, increasing the Reynolds number to $R e=15,000$ leads to an increase in PEC index and then a decreasing trend. In other words, increasing the Reynolds number has two consequences: on the one hand, it improves heat transfer, and on the other hand, it increases the pressure drop penalty. Thus, the compromise point for the maximum value of the PEC index occurs at $\operatorname{Re}=15,000$.

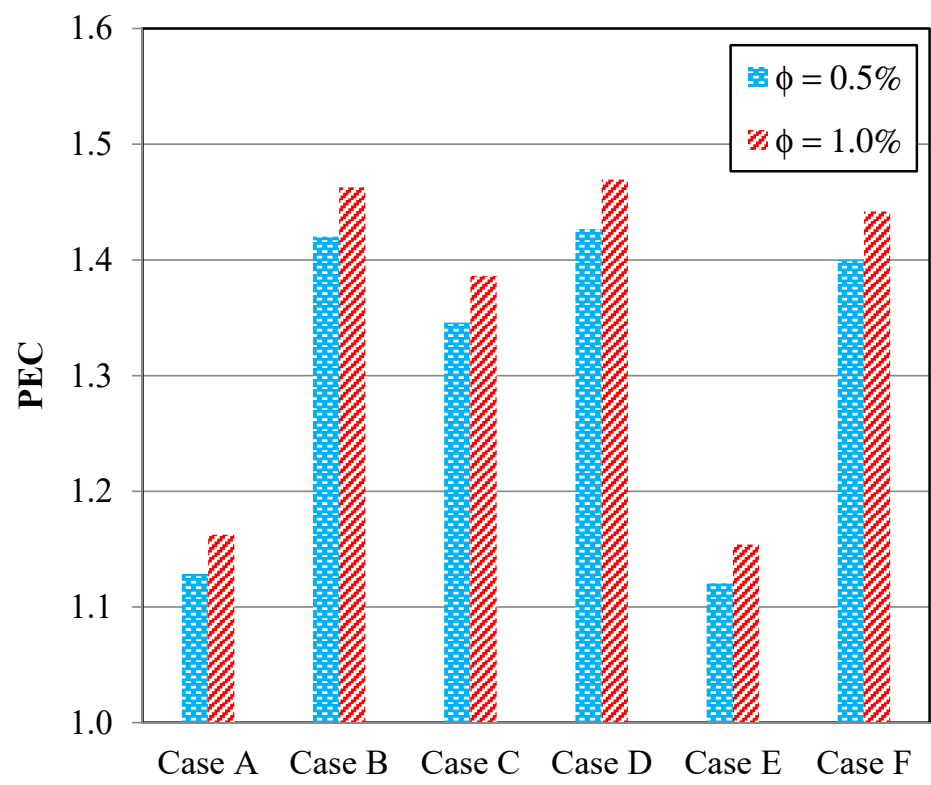

Configuration

Figure 32. PEC variation for optimum configurations of different cases at $\operatorname{Re}=11,000$. 


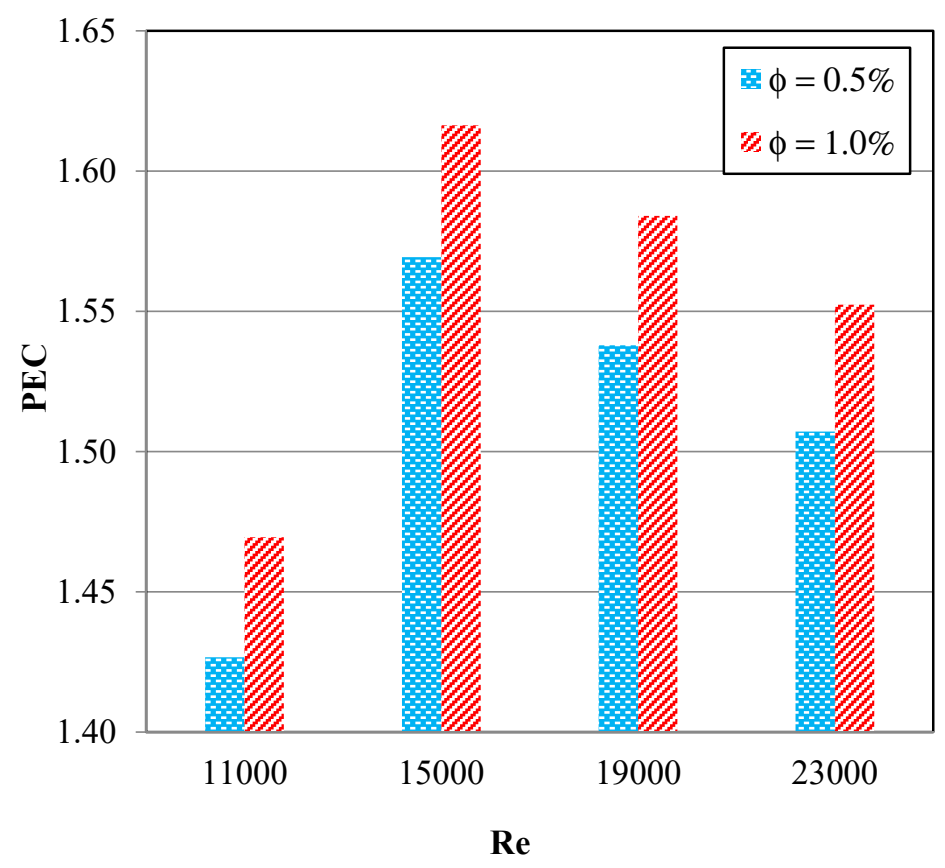

Figure 33. PEC variation versus different Reynolds numbers for optimum configurations of Case D.

\section{Conclusions}

The present study studies the effects of different wall shapes on the thermal-hydraulic characteristics of different channels filled with water based graphite- $\mathrm{SiO}_{2}$ hybrid nanofluid. The effects of different wall shapes on the thermalhydraulic characteristic of different channels filled with water based Graphite-SiO2 hybrid nanofluid is a challenging topic that, accordig to the literature review, is an area that needs to be worked on. In this study, performance evaluation criteria (PEC) index is employed as the goal parameter to attain the optimum geometry. Six different cases were studied in this paper. Each case has different geometric dimensions, which were investigated numerically to achieve the most efficient configuration. The length of the channel is $180 \mathrm{~mm}$, which is under a constant temperature of $T_{S}=450 \mathrm{~K}$. The heat transfer fluid (HTF) is water based graphite- $\mathrm{SiO}_{2}$ hybrid nanofluid, which enters the channel at $330 \mathrm{~K}$ at different flow velocities related to $\operatorname{Re}=11,000,15,000$, 19,000 , and 23,000. The grid mesh independence test was done in this research to achieve the most efficient grid mesh layout with the minimum error $(4 \%)$ and calculating time. Additionally, PEC index code validation was conducted, and it was found that there is a remarkable coincidence between the numerical data in the literature and the obtained numerical results from the current study. According to the obtained results, by changing geometrical parameters, the streamlines, temperature contours, kinetic energy contours, and velocity magnitude contours are affected significantly. As parameter $R$ or $F$ becomes smaller or as parameter $X 2$ becomes longer $(X=A, B, C, D, E$ and $F)$, the formation of vortices and local turbulence in the pipe increases and the flow mixing rate increases. On the one hand, this increases the heat transfer coefficient, and on the other hand leads to a greater pressure drop penalty. According to the results and calculation of the PEC index, the optimum configurations for different cases are: Case A: $R=15 \mathrm{~mm}$ and $A 2=24 \mathrm{~mm}$, Case $B: R=15 \mathrm{~mm}$ and $B 2=26 \mathrm{~mm}$, Case $C: R=13 \mathrm{~mm}$ and $B 2=22 \mathrm{~mm}$, Case $\mathrm{D}: R=13 \mathrm{~mm}$ and $B 2=24 \mathrm{~mm}$, Case E: $R=15 \mathrm{~mm}$ and $B 2=24 \mathrm{~mm}$, and Case F: $F=15 \mathrm{~mm}$. It was seen that Case D had the greatest PEC values, followed by Cases B, F, C, A, and E, respectively. Additionally, it can be seen that an increase in nanoparticle volume fraction leads to higher PEC values. Additionally, increasing the Reynolds number to $\operatorname{Re}=15,000$ leads to an increase in PEC index and then a decreasing trend. In other words, increasing the Reynolds number has two consequences: on the one hand, it improves heat transfer; on the other hand, it increases the pressure drop penalty. Therefore, the maximum value of the PEC index occurs at $\operatorname{Re}=15,000$. 
Author Contributions: Conceptualization, Y.K.; Data curation, Y.K. and A.T.; Formal analysis, Y.K. and A.T.; Investigation, Y.K., A.A. (Ahmad Alahmadi) and A.A. (Ali Alzaed); Methodology, Y.K., A.A. (Ahmad Alahmadi) and A.A. (Ali Alzaed); Supervision, Y.K., M.S. and G.C.; Writing-Original draft, Y.K., A.A. (Ahmad Alahmadi), A.A. (Ali Alzaed) and A.T.; Writing-Review \& editing, A.A. (Ahmad Alahmadi), M.S. and G.C. All authors have read and agreed to the published version of the manuscript.

Funding: This research received no external funding.

Acknowledgments: This work was supported by the Taif University Researchers Supporting Project, Taif University, Taif, Saudi Arabia, under Project TURSP-2020/121.

Conflicts of Interest: The authors declare no conflict of interest.

\section{Nomenclature}

$\begin{array}{ll}c_{p} & \text { Specific heat capacity }(\mathrm{J} / \mathrm{kg} . \mathrm{K}) \\ f & \text { Friction coefficient }(-) \\ g & \text { Gravitational acceleration }\left(\mathrm{m} / \mathrm{s}^{2}\right) \\ \varphi & \text { Volume fraction } \\ k & \text { Thermal conductivity }(\mathrm{W} / \mathrm{m} . \mathrm{K}) \\ N u & \text { Nusselt number }(-) \\ U_{m} & \text { Mass-averaged velocity }(\mathrm{m} / \mathrm{s}) \\ U_{s} & \text { Velocity of solid particles }(\mathrm{m} / \mathrm{s}) \\ U_{b f} & \text { Velocity of the base fluid }(\mathrm{m} / \mathrm{s}) \\ U_{d r} & \text { Drift velocity }(\mathrm{m} / \mathrm{s}) \\ \text { Greek Symbols } & \\ \varepsilon & \text { Turbulent dissipation }\left(\mathrm{m}^{2} / \mathrm{s}^{3}\right) \\ \eta & \text { Efficiency }(-) \\ \mu & \text { Viscosity }\left(\mathrm{N} \cdot \mathrm{s} / \mathrm{m}^{2}\right) \\ \mu_{t, m} & \text { Turbulent viscosity }\left(\mathrm{N} \cdot \mathrm{s} / \mathrm{m}^{2}\right) \\ P & \text { Pressure }(\mathrm{Pa}) \\ \operatorname{Re} & \text { Reynolds number }(-) \\ \text { Subscripts } & \\ n f & \text { Nanofluid } \\ n p & \text { Nanoparticle } \\ s & \text { Solid }\end{array}$

\section{References}

1. Parsa, S.M.; Yazdani, A.; Dhahad, H.; Alawee, W.H.; Hesabi, S.; Norozpour, F.; Ali, H.M.; Afrand, M. Effect of Ag, Au, TiO 2 metallic/metal oxide nanoparticles in double-slope solar stills via thermodynamic and environmental analysis. J. Clean. Prod. 2021, 311, 127689. [CrossRef]

2. Eshgarf, H.; Kalbasi, R.; Maleki, A.; Shadloo, M.S.; Karimipour, A. A review on the properties, preparation, models and stability of hybrid nanofluids to optimize energy consumption. J. Therm. Anal. Calorim. 2021, 144, 1959-1983. [CrossRef]

3. Parsa, S.M.; Rahbar, A.; Koleini, M.; Aberoumand, S.; Afrand, M.; Amidpour, M. A renewable energy-driven thermoelectricutilized solar still with external condenser loaded by silver/nanofluid for simultaneously water disinfection and desalination. Desalination 2020, 480, 114354. [CrossRef]

4. Keepaiboon, C.; Dalkilic, A.S.; Mahian, O.; Ahn, H.S.; Wongwises, S.; Mondal, P.K.; Shadloo, M.S. Two-phase flow boiling in a microfluidic channel at high mass flux. Phys. Fluids 2020, 32, 093309. [CrossRef]

5. Wang, N.; Maleki, A.; Nazari, M.A.; Tlili, I.; Shadloo, M.S. Thermal Conductivity Modeling of Nanofluids Contain MgO Particles by Employing Different Approaches. Symmetry 2020, 12, 206. [CrossRef]

6. Garbadeen, I.; Sharifpur, M.; Slabber, J.; Meyer, J. Experimental study on natural convection of MWCNT-water nanofluids in a square enclosure. Int. Commun. Heat Mass Transf. 2017, 88, 1-8. [CrossRef]

7. Rostami, S.; Kalbasi, R.; Talebkeikhah, M.; Goldanlou, A.S. Improving the thermal conductivity of ethylene glycol by addition of hybrid nano-materials containing multi-walled carbon nanotubes and titanium dioxide: Applicable for cooling and heating. J. Therm. Anal. Calorimetry 2021, 143, 1701-1712. [CrossRef]

8. Yan, S.R.; Golzar, A.; Sharifpur, M.; Meyer, J.P.; Liu, D.H.; Afrand, M. Effect of U-shaped absorber tube on thermal-hydraulic performance and efficiency of two-fluid parabolic solar collector containing two-phase hybrid non-Newtonian nanofluids. Int. J. Mech. Sci. 2020, 185, 105832. [CrossRef] 
9. Aghakhani, S.; Ghasemi, B.; Pordanjani, A.H.; Wongwises, S.; Afrand, M. Effect of replacing nanofluid instead of water on heat transfer in a channel with extended surfaces under a magnetic field. Int. J. Numer. Methods Heat Fluid Flow 2019, 29, $1249-1271$. [CrossRef]

10. Giwa, S.; Sharifpur, M.; Goodarzi, M.; Alsulami, H.; Meyer, J.P. Influence of base fluid, temperature, and concentration on the thermophysical properties of hybrid nanofluids of alumina-ferrofluid: Experimental data, modeling through enhanced ANN, ANFIS, and curve fitting. J. Therm. Anal. Calorim. 2021, 143, 4149-4167. [CrossRef]

11. Aghakhani, S.; Pordanjani, A.H.; Afrand, M.; Sharifpur, M.; Meyer, J.P. Natural convective heat transfer and entropy generation of alumina/water nanofluid in a tilted enclosure with an elliptic constant temperature: Applying magnetic field and radiation effects. Int. J. Mech. Sci. 2020, 174, 105470. [CrossRef]

12. Ibrahim, M.; Saeed, T.; Chu, Y.-M.; Ali, H.M.; Cheraghian, G.; Kalbasi, R. Comprehensive study concerned graphene nano-sheets dispersed in ethylene glycol: Experimental study and theoretical prediction of thermal conductivity. Powder Technol. 2021, 386, 51-59. [CrossRef]

13. Pordanjani, A.H.; Aghakhani, S.; Afrand, M.; Mahmoudi, B.; Mahian, O.; Wongwises, S. An updated review on application of nanofluids in heat exchangers for saving energy. Energy Convers. Manag. 2019, 198, 111886. [CrossRef]

14. Komeilibirjandi, A.; Raffiee, A.H.; Maleki, A.; Nazari, M.A.; Shadloo, M.S. Thermal conductivity prediction of nanofluids containing $\mathrm{CuO}$ nanoparticles by using correlation and artificial neural network. J. Therm. Anal. Calorim. 2020, 139, 2679-2689. [CrossRef]

15. Pordanjani, A.H.; Aghakhani, S. Numerical Investigation of Natural Convection and Irreversibilities between Two Inclined Concentric Cylinders in Presence of Uniform Magnetic Field and Radiation. Heat Transf. Eng. 2021, 1-21. [CrossRef]

16. Yan, S.-R.; Aghakhani, S.; Karimipour, A. Influence of a membrane on nanofluid heat transfer and irreversibilities inside a cavity with two constant-temperature semicircular sources on the lower wall: Applicable to solar collectors. Phys. Scr. 2020, 95, 085702. [CrossRef]

17. Ghalandari, M.; Maleki, A.; Haghighi, A.; Shadloo, M.S.; Nazari, M.A.; Tlili, I. Applications of nanofluids containing carbon nanotubes in solar energy systems: A review. J. Mol. Liq. 2020, 313, 113476. [CrossRef]

18. Parsa, S.M. Reliability of thermal desalination (solar stills) for water/wastewater treatment in light of COVID-19 (novel coronavirus "SARS-CoV-2") pandemic: What should consider? Desalination 2021, 512, 115106. [CrossRef]

19. Rostami, S.; Aghakhani, S.; Pordanjani, A.H.; Afrand, M.; Cheraghian, G.; Oztop, H.F.; Shadloo, M.S. A Review on the Control Parameters of Natural Convection in Different Shaped Cavities with and Without Nanofluid. Processes 2020, 8, 1011. [CrossRef]

20. Parsa, S.M.; Rahbar, A.; Koleini, M.; Javadi, Y.D.; Afrand, M.; Rostami, S.; Amidpour, M. First approach on nanofluid-based solar still in high altitude for water desalination and solar water disinfection (SODIS). Desalination 2020, 491, 114592. [CrossRef]

21. Nakharintr, L.; Naphon, P. Magnetic field effect on the enhancement of nanofluids heat transfer of a confined jet impingement in mini-channel heat sink. Int. J. Heat Mass Transf. 2017, 110, 753-759. [CrossRef]

22. Ashorynejad, H.R.; Zarghami, A. Magnetohydrodynamics flow and heat transfer of Cu-water nanofluid through a partially porous wavy channel. Int. J. Heat Mass Transf. 2018, 119, 247-258. [CrossRef]

23. Dormohammadi, R.; Farzaneh-Gord, M.; Ebrahimi-Moghadam, A.; Ahmadi, M.H. Heat transfer and entropy generation of the nanofluid flow inside sinusoidal wavy channels. J. Mol. Liq. 2018, 269, 229-240. [CrossRef]

24. Saeed, M.; Kim, M.-H. Heat transfer enhancement using nanofluids (Al2O3-H2O) in mini-channel heatsinks. Int. J. Heat Mass Transf. 2018, 120, 671-682. [CrossRef]

25. Dalkılıç, A.S.; Türk, O.A.; Mercan, H.; Nakkaew, S.; Wongwises, S. An experimental investigation on heat transfer characteristics of graphite-SiO2/water hybrid nanofluid flow in horizontal tube with various quad-channel twisted tape inserts. Int. Commun. Heat Mass Transf. 2019, 107, 1-13. [CrossRef]

26. Saba, F.; Ahmed, N.; Khan, U.; Mohyud-Din, S.T. A novel coupling of (CNT-Fe3O4/H2O) hybrid nanofluid for improvements in heat transfer for flow in an asymmetric channel with dilating/squeezing walls. Int. J. Heat Mass Transf. 2019, 136, 186-195. [CrossRef]

27. Ajeel, R.K.; Salim, W.I.; Hasnan, K. Experimental and numerical investigations of convection heat transfer in different channels using alumina nanofluid under a turbulent flow regime. Chem. Eng. Res. Des. 2019, 148, 202-217. [CrossRef]

28. Gholami, M.; Nazari, M.R.; Talebi, M.H.; Pourfattah, F.; Akbari, O.A.; Toghraie, D. Natural convection heat transfer enhancement of different nanofluids by adding dimple fins on a vertical channel wall. Chin. J. Chem. Eng. 2020, 28, 643-659. [CrossRef]

29. Shah, Z.; Khan, A.; Khan, W.; Alam, M.K.; Islam, S.; Kumam, P.; Thounthong, P. Micropolar gold blood nanofluid flow and radiative heat transfer between permeable channels. Comput. Methods Programs Biomed. 2020, 186, 105197. [CrossRef]

30. Ajeel, R.K.; Salim, W.I.; Sopian, K.; Yusoff, M.Z.; Hasnan, K.; Ibrahim, A.; Al-Waeli, A.H. Turbulent convective heat transfer of silica oxide nanofluid through different channels: An experimental and numerical study. Int. J. Heat Mass Transf. 2019, 145, 118806. [CrossRef]

31. Ajeel, R.K.; Salim, W.S.I.W.; Hasnan, K. Influences of geometrical parameters on the heat transfer characteristics through symmetry trapezoidal-different channel using SiO2-water nanofluid. Int. Commun. Heat Mass Transf. 2019, 101, 1-9. [CrossRef]

32. Ajeel, R.K.; Salim, W.I.; Hasnan, K. Numerical investigations of heat transfer enhancement in a house shaped-different channel: Combination of nanofluid and geometrical parameters. Therm. Sci. Eng. Prog. 2020, 17, 100376. [CrossRef]

33. Salimpour, M.R.; Kalbasi, R.; Lorenzini, G. Constructal multi-scale structure of PCM-based heat sinks. Contin. Mech. Thermodynamics 2017, 29, 477-494. [CrossRef] 
34. Salari, A.; Kazemian, A.; Ma, T.; Hakkaki-Fard, A.; Peng, J. Nanofluid based photovoltaic thermal systems integrated with phase change materials: Numerical simulation and thermodynamic analysis. Energy Convers. Manag. 2020, 205, 112384. [CrossRef]

35. Al-Ansary, H.; Zeitoun, O. Numerical study of conduction and convection heat losses from a half-insulated air-filled annulus of the receiver of a parabolic trough collector. Sol. Energy 2011, 85, 3036-3045. [CrossRef]

36. Arani, A.A.A.; Sadripour, S.; Kermani, S. Nanoparticle shape effects on thermal-hydraulic performance of boehmite alumina nanofluids in a sinusoidal-wavy mini-channel with phase shift and variable wavelength. Int. J. Mech. Sci. 2017, 128-129, 550-563. [CrossRef]

37. Sadripour, S. 3D numerical analysis of atmospheric-aerosol/carbon-black nanofluid flow within a solar air heater located in Shiraz, Iran. Int. J. Numer. Methods Heat Fluid Flow 2018, 29, 1378-1402. [CrossRef]

38. Sadripour, S.; Chamkha, A.J. The effect of nanoparticle morphology on heat transfer and entropy generation of supported nanofluids in a heat sink solar collector. Therm. Sci. Eng. Prog. 2019, 9, 266-280. [CrossRef]

39. Kim, D.; Kwon, Y.; Cho, Y.; Li, C.; Cheong, S.; Hwang, Y.; Lee, J.; Hong, D.; Moon, S. Convective heat transfer characteristics of nanofluids under laminar and turbulent flow conditions. Curr. Appl. Phys. 2009, 9, e119-e123. [CrossRef]

40. Giwa, S.; Sharifpur, M.; Meyer, J. Experimental study of thermo-convection performance of hybrid nanofluids of $\mathrm{Al}_{2} \mathrm{O}_{3}-$ MWCNT/water in a differentially heated square cavity. Int. J. Heat Mass Transf. 2020, 148, 119072. [CrossRef]

41. Leong, W.; Hollands, K.; Brunger, A. Experimental Nusselt numbers for a cubical-cavity benchmark problem in natural convection. Int. J. Heat Mass Transf. 1999, 42, 1979-1989. [CrossRef]

42. Yang, S.; Ordonez, J. 3D thermal-hydraulic analysis of a symmetric wavy parabolic trough absorber pipe. Energy 2019, 189, 116320. [CrossRef] 